\title{
Downward Nominal Wage Rigidity in the United States: New Evidence from Worker-Firm Linked Data
}

\author{
by
}

\section{André Kurmann \\ Drexel University}

\author{
Erika McEntarfer \\ U.S. Cens us Bureau
}

\section{CES 19-07 February, 2019}

The research program of the Center for Economic Studies (CES) produces a wide range of economic analyses to improve the statistical programs of the U.S. Census Bureau. Many of these analyses take the form of CES research papers. The papers have not undergone the review accorded Census Bureau publications and no endorsement should be inferred. Any opinions and conclusions expressed herein are those of the author(s) and do not necessarily represent the views of the U.S. Census Bureau. All results have been reviewed to ensure that no confidential information is disclosed. Republication in whole or part must be cleared with the authors.

To obtain information about the series, see www.census.gov/ces or contact Christopher Goetz, Editor, Discussion Papers, U.S. Census Bureau, Center for Economic Studies 5K028B, 4600 Silver Hill Road, Washington, DC 20233, CES.Working.Papers@ census.gov. To subscribe to the series, please click here. 


\begin{abstract}
This paper examines the extent and consequences of Downward Nominal Wage Rigidity (DNWR) using administrative worker-firm linked data from the Longitudinal Employer Household Dynamics (LEHD) program for a large representative U.S. state. Prior to the Great Recession, only $7-8 \%$ of job stayers are paid the same nominal hourly wage rate as one year earlier - substantially less than previously found in survey-based data - and about $20 \%$ of job stayers experience a wage cut. During the Great Recession, the incidence of wage cuts increases to 30\%, followed by a large rise in the proportion of wage freezes to $16 \%$ as the economy recovers. Total earnings of job stayers exhibit even fewer zero changes and a larger incidence of reductions than hourly wage rates, due to systematic variations in hours worked. The results are consistent with concurrent findings in the literature that reductions in base pay are exceedingly rare but that firms use different forms of nonbase pay and variations in hours worked to flexibilize labor cost. We then exploit the worker-firm link of the LEHD and find that during the Great Recession, firms with indicators of DNWR reduced employment by about $1.2 \%$ more per year. This negative effect is driven by significantly lower hiring rates and persists into the recovery. Our results suggest that despite the relatively large incidence of wage cuts in the aggregate, DNWR has sizable allocative consequences.
\end{abstract}

\footnotetext{
* First draft:May 12, 2017. We are gratefulto Cynthia Forland and the Washington Employment Security Department for permis sion to u se the Washington dat a for this project and feedback on our work. We also thank Jim Spletzer for earlier involvement in the project; Joe Altonji, Cynthia Doniger, Erik Hurst, Theodore Papageorgiou and Gary Solon for their insightful comments and discussions; and many seminar and conferenceparticipants for their comments. The views expressed in this paper do not necessarily represent the views of the U.S. Census Bureau. All results have been reviewed to ensure that no con dential information is disclosed. Output was released under DRB bypass numbers DRB-0096B-CDAR-06252018 and DRB-B0106-CDAR-20180716. Contact information: kurmann.andre@drexel.edu and erika.mcentarfer@census.gov.
} 


\section{Introduction}

Dating back to Keynes (1936), one of the central debates in macroeconomics concerns the question of whether wages are rigid and if so, whether it matters for business cycle fluctuations. A large literature following Keynes argues that even in times of high unemployment, firms are reluctant to cut money wages of their employees and instead respond to adverse shocks by reducing employment. This Downward Nominal Wage Rigidity (DNWR) hypothesis provides an important justification for policy intervention and features prominently as an explanation for the large employment losses during the Great Recession as well as the slow wage growth thereafter. ${ }^{1}$ In sharp contrast, a concurrent literature based on the work by Becker (1962) shows that while DNWR may arise endogenously in long-term employment relationships, this rigidity is in many cases separate from the present value of labor compensation and therefore does not play an allocative role. ${ }^{2}$

Despite the centrality of the debate, there is surprisingly little consensus on the extent of DNWR and even less so on the consequences of DNWR. This lack of consensus is in large part due to limitations with the survey-based data that has historically been used to study DNWR. First, self-reported wages from surveys are subject to potentially important measurement issues that have led many to question the reliability of wage rigidity estimates coming from these data sources. ${ }^{3}$ Second, at least for the U.S., the survey-based data typically does not contain information about firm employment, thus making it difficult if not impossible to test for the allocative effects of DNWR.

In this paper, we use administrative worker-firm linked data from the Longitudinal Employer Household Dynamics (LEHD) program of the U.S. Census Bureau to provide new evidence on the extent and consequences of DNWR. The data consists of worker-specific earnings records that employers submit to state unemployment insurance (UI) offices for the purpose of determining unemployment benefits. We concentrate our analysis on one large, nationally representative state - Washington - because unlike most other states, Washing-

\footnotetext{
${ }^{1}$ See for example Krugman (2012), Economist (2014), or Yellen (2016). The DNWR hypothesis not only implies that fiscal stimulus has large effects during recessions but also that moderate inflation can help, as Tobin (1972) put it, "grease the wheels of the economy" by making DNWR constraints bind less often.

${ }^{2}$ See Barro (1977) for a well-known critique of the allocative effects of nominal wage contract models; and Pissarides (2009) or Basu and House (2016) for similar arguments in a modern labor search context.

${ }^{3}$ Prominent studies based on household survey data from the Current Population Survey (CPS), the Panel Study of Income Dynamics (PSID), and the Survey of Income and Program Participation (SIPP) include McLaughlin (1994); Akerlof et al. (1996) Card and Hyslop (1997); Kahn (1997); Altonji and Devereux (2000); Gottschalk (2005); Dickens et al. (2007); Elsby (2009); Barratieri et al. (2014); Daly and Hobijn (2014) and Elsby et al. (2016). Work based on firm survey data from the Employer Cost Index (ECI) comes from Lebow et al. (2003) and Fallick et al. (2016). See Elsby et al. (2016) for a review of these studies and a discussion of how measurement error can bias estimates of DNWR either upward or downward.
} 
ton's UI office requires employers to provide information not only on earnings but also on hours. This allows us to calculate the change in average hourly wage for each worker, which is the metric most relevant for the DNWR debate, and to study how changes in wage rates and hours worked relate to changes in total earnings. The available sample extends from 1998 to 2014 and therefore includes both the Great Recession and the 2001 recession.

Our LEHD data offers three key advantages that allow us to address the above highlighted limitations of survey data. First, the administrative nature of the UI records means that our data, while not entirely free of error, is much less prone to measurement issues. As described in detail in Section 2, the high quality of the data applies not just to earnings but also to hours, presumably because Washington uses hours to determine eligibility for unemployment benefits and provides very specific reporting instructions to employers. ${ }^{4}$ Second, LEHD earnings include not just base pay but all forms of monetary compensation disbursed to workers, including bonuses, overtime, tips and commissions. This is important when estimating the extent of DNWR since firms may use variable pay schemes on top of base pay to incentivize workers and flexibilize labor cost. Third, the LEHD data follows firms and all workers employed by them over time, covering more than $95 \%$ of private-sector employment. This worker-firm link allows us to construct indicators of DNWR at the firm level and to relate them to firm employment outcomes. We are therefore able to address the key question of the literature: Does DNWR represent a constraint with negative labor market consequences or does DNWR not play any allocative role?

Section 3 begins by documenting the wage change distribution of job stayers; i.e. workers who remain employed with the same firm. ${ }^{5}$ We find that prior to the Great Recession, only $7-8 \%$ of job stayers are paid the same average wage per quarter as one year earlier and about $20 \%$ of job stayers experience a wage cut. At the same time, the proportion and magnitude of these wage cuts is noticeably smaller than what a symmetric distribution would predict; i.e. the wage change distribution is positively skewed. During the Great Recession, the wage change distribution shifts to the left and becomes more symmetric, with the proportion of wage cuts increasing to $30 \%$. This is followed by a large increase in the proportion of zero wage changes as the economy starts to recover, peaking at $16 \%$ in 2010 before

\footnotetext{
${ }^{4}$ Measurement error in self-reported hours has long been considered one of the most important limitations of survey data (e.g. Bound et al., 1991 and Heckman, 1993). As a result, many survey-based studies analyze wage rates of hourly paid workers and earnings of salaried workers separately. While interesting, this clearly limits the analysis for two reasons. First, for hourly paid workers, one cannot study the importance of irregular payments such as bonuses for wage changes. Second, for salaried workers, earnings changes provide an inaccurate measure of wage changes when hours vary, which turns out to be quite common.

${ }^{5}$ We focus on job stayers because the DNWR debate primarily concerns wage rigidity in ongoing employment relationships. Wages of job movers are much more flexible a point to which we return below.
} 
gradually returning towards its pre-recession average. Similarly timed but substantially smaller changes in the wage change distribution occur around the 2001 recession as well as within different firm size classes and industries. ${ }^{6}$

The results differ substantially from previous results based on U.S. household survey data. For instance, compared to Daly and Hobijn (2014) and Elsby et al. (2016) who use CPS data to analyze a similar time period as we do, the proportion of zero wage changes in our data is less than half prior to the Great Recession even though our wage change distribution is otherwise substantially more concentrated. And while these studies also note an increase in zero wage changes during the recovery, this increase is more than twice as large in our data. As discussed in the main text, these differences likely reflect a combination of measurement error and incomplete accounting of non-base pay components.

Next, we analyze earnings and hours changes of job stayers. Compared to the wage change distribution, the earnings change distribution is more dispersed, containing an even smaller proportion of zero changes and a larger proportion of negative changes. During the Great Recession, the proportion of job stayers experiencing a cut in annual earnings rises as high as 39\% and the earnings change distribution becomes negatively skewed. These differences are due to systematic changes in hours, which on average account for about $70 \%$ of earnings cuts but for only about $50 \%$ of earnings increases.

Section 4 exploits the worker-firm link of the LEHD to test whether firms with indicators of DNWR reduce employment by more in response to a negative shock than firms without such indicators. Inference is complicated by the fact that firms with indicators of DNWR may be systematically different along other dimensions that affect employment dynamics. Furthermore, as demonstrated by Elsby (2009), if DNWR indeed represents a constraint on wage setting, then this provides firms with an incentive to compress wage increases so as to reduce the risk of the constraint binding in the future. ${ }^{7}$ All else equal, it is therefore unclear whether DNWR-constrained firms exhibit on average lower employment growth than unconstrained firms. We address these challenges by constructing indicators of DNWR at the firm level prior to the Great Recession and estimating the effect of these DNWR indicators on firm employment dynamics in response to the Great Recession - a large unexpected negative

\footnotetext{
${ }^{6}$ At the same time, we find systematic differences by firm size and industry, with large firms and firms in manufacturing, professional services, finance and insurance exhibiting more flexible wage change distributions. Since small firms are affected more negatively by the Great Recession than large firms, the increase in the proportion of zero wage changes as the economy starts to recover is not driven by composition.

${ }^{7}$ One can similarly show that DNWR-constrained firms have an incentive to adopt a higher productivity threshold for hiring, which further counteracts negative effects of DNWR on average employment growth. Section 4 provides a detailed discussion of these issues.
} 
shock to which DNWR-constrained firms should be more vulnerable - while controlling for a rich set of industry- and firm-level observables. ${ }^{8}$ We find compelling evidence that firms with pre-recession indicators of DNWR exhibit significantly lower employment growth during the Great Recession. According to our preferred specification which includes a firm fixed effect, this negative effect is estimated to about $1.2 \%$ per year and is primarily driven by lower hiring rates that persist well into the recovery. These results are robust to a host of recession-specific firm controls, industry shocks, and different ways of measuring DNWR. Furthermore, we show that the pre-recession employment growth distribution of firms with indicators of DNWR looks essentially identical to the one of firms without indicators of DNWR. This makes it unlikely that the negative employment effects of DNWR during the Great Recession are driven by confounding factors.

The results coming out of our analysis have important implications for macro-labor theories of the business cycle and in particular the Great Recession. First, our results suggest that once all forms of monetary compensation are taken into account, nominal wage cuts for job stayers are surprisingly frequent. This contradicts the hypothesis of a strongly binding DNWR constraint that figures prominently in many policy discussions and is also a key ingredient in a growing number of business cycle models. ${ }^{9}$

Second, the small and time-varying incidence of zero wage changes represents a challenge for New Keynesian models, which typically ascribe an important role to nominal wage rigidity. Indeed, when viewed through the lens of a canonical Calvo model of wage setting, our pre-recession estimate of 7-8\% of zero wage changes implies an adjustment probability of about 0.45 per quarter - much higher than what is typically required in these models to generate large fluctuations (see e.g. Christiano et al., 2005 or Smets and Wouters, 2007). ${ }^{10}$ In turn, the increase in zero wage changes to $16 \%$ as the economy starts to recover from the Great Recession provides strong evidence that wage rigidity is state-dependent. This suggests that the assumption of time-dependent wage setting adopted in most New Keynesian models is unlikely to provide a good approximation.

Third, the larger downward flexibility of hours relative to hourly wage rates suggests that reductions in hours are frequently used to cut labor costs, especially during the Great

\footnotetext{
${ }^{8}$ This strategy is similar in spirit to the one adopted in a recent literature investigating how pre-crisis financial or organizational conditions affect a firm's ability to cope with the unexpected negative Great Recession shock. See for example Chodorow-Reich (2014) and Giroud and Mueller (2017) on financial frictions; Alfaro and Chen (2012) on ownership; or Aghion et al. (2017) on decentralization.

${ }^{9}$ See Section 3 for a discussion of this literature.

${ }^{10}$ These calculations do not take into account that job movers, which are not distinguished from job stayers in New Keynesian models, have considerably more flexible wages than job stayers.
} 
Recession, thereby mitigating possible negative employment effects of DNWR constraints. More generally, our results imply that systematic hours changes are a key driver behind the countercyclical earnings risk faced by job stayers - a finding that is interesting in light of the new literature on earnings risk initiated by Guvenen et al. (2014) - and that hours variation are a potentially important margin to understand employment fluctuations - consistent with recent results by Borowczyk-Martins and Lalé (2018).

Fourth, while the proportion of wage freezes is relatively small and wage cuts appear to be quite frequent, our regression results suggest that for at least a subset of firms, DNWR represents a constraint with economically meaningful consequences. Abstracting from equilibrium effects that are differenced out by the regressions, the estimated negative effect for firms with indicators of DNWR accounts for about $1 \%$ of the overall $6 \%$ decline in Washington's employment during the Great Recession. Why exactly this constraint arises and how it affects hiring and separations in models with long-term employment relationships remain open questions. We therefore consider our results first and foremost as a set of stylized facts that macro-labor theories of the business cycle should aspire to match. ${ }^{11}$

Related literature: Aside from the aforementioned survey-based literature on DNWR, our paper relates to a select number of studies analyzing nominal wage rigidity for the U.S. with administrative data. In earlier, unpublished work with Jim Spletzer (Kurmann et al., 2016), we construct the earnings change distribution of job stayers for a 30-state sample of the LEHD data from 1999 to 2011 as well as the hourly wage change distribution for three states with hours information from 2010 to 2011. The present paper focuses on Washington state because Washington's hours records appear to be of uniformly high quality and the available data extends back to the late 1990s. ${ }^{12}$ The longer sample is crucial to document large time variations in the wage change distribution since the Great Recession and to test for allocative consequences of DNWR. Another paper that has recently started using Washington data is Jardim et al. (2018). ${ }^{13}$ Their analysis confirms our basic results on the wage change distribution, which is useful given the confidential nature of the LEHD data. At the same

\footnotetext{
${ }^{11}$ Earlier versions of the paper contained a dynamic labor demand model with efficiency wages as proposed by Elsby (2009) that is capable of matching at least qualitatively the different results. The model is omitted from the current version to save on space but is available upon request.

${ }^{12}$ Aside from Washington, the only other states reporting information on hours to the LEHD program are Minnesota, Oregon and Rhode Island. Oregon and Rhode Island and Oregon only began collecting hours data recently; and Minnesota did not send Census hours data for several years in the middle of our time period of interest.

${ }^{13}$ Other work using the Washington data are Jardim et al. (2017) who analyze the consequences of minimum wage increases in Seattle, WA; Lachowska et al. (2017) who study the role of hours variations for earnings losses after mass layoff events; and Lachowska et al. (2018) who test the quality of the hours data and conclude, as we do, that this quality is high.
} 
time, their analysis is much more limited in scope. Lastly, in ongoing work that is highly complementary to ours, Grigsby et al. (2018) use data from ADP, the largest U.S. payroll processing company, to study nominal wage changes of job stayers and job changers. Their data has the advantage that it provides detailed information on base pay versus different forms of non-base pay. At the same time, the accuracy of the hours data reported by ADP is unknown, which is why the authors focus primarily on the relative importance and rigidity of different components of pay. For the 2008-16 period, they find that about $35 \%$ of job stayers have the same base pay (defined as the worker's contract rate per pay cycle) as a year earlier and that reductions in base pay are rare. In sharp contrast, non-base pay components of compensation are much more flexible - both upward and downward. Once bonuses and other non-base pay components are included, compensation becomes substantially more flexible and their results look surprisingly similar to ours even though non-base pay constitutes only a small fraction of compensation for the average worker. ${ }^{14}$ This highlights the importance of including all forms of compensation when studying DNWR and at the same time suggests that the extent to which firms can reduce labor costs by cutting non-base pay is limited.

There are also a number of studies that use administrative data for other countries to study wage dynamics; e.g. Nickell and Quintini (2003) and Elsby et al. (2016) for the U.K.; Castellano et al. (2004) for Mexico; Carneiro et al. (2014) for Portugal; Bihan et al. (2012) for France; Siggurdsson and Sigurdardottir (2016) for Iceland; Park and Shin (2017) for South Korea; and Ehrlich and Montes (2018) for Germany. Consistent with our results, these studies generally find that the proportion of zero wage changes is state-dependent and substantially smaller than typically found in survey data; and that the incidence of nominal wage cuts is quite high, ranging between $15 \%$ and $25 \% .{ }^{15}$ The only paper on this list that attempts to test for the allocative consequences of DNWR across firms is Ehrlich and Montes (2018). As in our case, they find sizable negative employment effects of DNWR even though their empirical approach is quite different.

\section{Data}

The LEHD data we use consists of worker-specific earnings records that employers submit every quarter to state UI offices for the purpose of determining unemployment benefits.

\footnotetext{
${ }^{14}$ Section 3 provides a detailed comparison of our results with Grigsby et al. (2018).

${ }^{15}$ The exceptions are Mexico and Portugal where wage cuts are much less frequent and the incidence of wage freezes during recessions much higher, primarily because the fraction of minimum wage earners is large (Mexico) and wage cuts are explicitly prohibited (Portugal). Also see the review by Elsby and Solon (2018).
} 
States provide these records along with establishment industry affiliation and location to the U.S. Census Bureau where it is augmented with information on worker age, gender, race, and place of residence. The resulting dataset covers over $95 \%$ of private-sector workers and forms the basis for several publicly available labor market statistics. ${ }^{16}$ We focus on the State of Washington because their UI office collects high-quality data not only on earnings but also on hours worked, and the data is available for a period extending back to the late 1990s.

In what follows, we describe the construction of wage and earnings changes for job stayers; provide details on the individual earnings records and the quality of Washington's hours data; and report basic characteristics and representativeness of our samples.

\subsection{Wage, earnings, and hours changes of job stayers}

Our primary measure of wage changes is the log difference of the average nominal hourly wage rate relative to four quarters earlier; i.e. for each job stayer $i$ and quarter $t$, we compute $\triangle \ln W_{i t}=\ln W_{i t}-\ln W_{i t-4}$, where $W_{i t}$ is obtained by dividing reported quarterly earnings $E_{i t}$ with reported quarterly hours $H_{i t}$. We call this the four-quarter change. ${ }^{17}$

For earnings and hours, we could also compute four-quarter changes. However, firms report to the UI system earnings and hours paid rather than accrued during the quarter. Whenever the number of pay periods per quarter differs, this results in potentially large spurious changes in earnings and hours that are difficult to correct because firms often have different payroll schedules for different types of employees. ${ }^{18}$ On an annual basis, this payperiod problem does not occur. For earnings and hours, we therefore only consider year-toyear changes; i.e. for earnings, we compute $\triangle \ln E_{i t}=\ln \left(\sum_{q=0}^{3} E_{i t+q}\right)-\ln \left(\sum_{q=-4}^{-1} E_{i t+q}\right)$ and likewise for hours.

In order to be retained as a job stayer in our analysis, a worker has to remain with the same employer, defined by a state tax identifier (SEIN), for at least ten consecutive quarters: the eight quarters for which we compute year-to-year changes plus the last quarter

\footnotetext{
${ }^{16}$ The LEHD data also covers some state and local government employees but we do not consider them here. For a description, see Abowd et al. (2009) and Vilhuber and McKinney (2014). Census uses the data to generate, among others, the publicly available Quarterly Workforce Indicators, LEHD Origin-Destination Employment Statistics, and Job-to-Job Flows.

${ }^{17}$ We could also consider quarter-to-quarter wage changes. However, bonuses and other non-base pay components are often recorded in a particular quarter even though they reflect compensation for an entire year.

${ }^{18}$ As an example, consider a worker with 26 bi-weekly pay periods per year. Two quarters will have six pay periods and two quarters will have seven pay periods. For the hourly wage rate, this problem does not arise since we construct it by dividing earnings by hours.
} 
preceding the first year and the first quarter following the second year. ${ }^{19}$ The beginning and end quarter are part of the selection criteria so as to ensure that employment spells last for at least two full years, which is important to correctly measure year-to-year earnings and hours changes. This definition of job stayers implies that our analysis focuses on relatively long-lived employment relationships for which implicit contracting or efficiency wage considerations are more relevant than for shorter-term employment relationships. Our results are therefore likely to represent an upper bound on the extent of DNWR.

\subsection{Earnings records in the LEHD}

As highlighted in the introduction, the administrative nature of the LEHD data means that the earnings records, while not entirely free from error or noise, are not subject to the type of rounding and recall errors that have been shown to affect earnings data from household surveys. Furthermore, LEHD earnings include all forms of monetary compensation disbursed by employers, including bonuses, overtime, tips and commissions, and the value of meals and lodging where supplied. Apart from employer-covered benefits, LEHD earnings therefore capture total labor cost. In contrast, surveys typically ask only about base pay or usual earnings. This difference matters because variations in compensation beyond base pay may play an important role for measuring DNWR.

Of course, it would be interesting to know about the relative importance of base pay versus other forms of compensation and how these components adjust over time. Unfortunately, the LEHD is limited in this respect because UI offices do not require employers to report separate information on the different components of earnings. ${ }^{20}$ Likewise, employers do not report whether an employee is paid by the hour or is salaried. We believe that the comprehensive nature of the LEHD earnings records and, as discussed next, the high-quality measure of hours worked largely outweigh these limitations since it allows us to compute variations in total compensation per unit of work - the metric most relevant for the DNWR debate.

\subsection{The quality of Washington's hours data}

Washington is unique in that it uses hours worked in the previous year to determine UI benefit eligibility and provides detailed instructions to employers on how to report hours.

\footnotetext{
${ }^{19}$ Our state-firm definition of employers is predicated by the fact that individual worker information is available only at the SEIN level and not at the establishment level.

${ }^{20}$ We will discuss independent evidence by Grigsby et al. (2018) on the relative importance and variability of different components of pay in Section 3.
} 
For all hourly paid workers as well as salaried and commissioned workers for which hours are explicitly tracked, employers are instructed to report hours worked, including overtime hours and hours that would have been worked while on paid leave. For salaried and commissioned workers for which hours are not tracked, employers are instructed to report 40 hours per week. ${ }^{21}$ Failing to report, reporting late or in the wrong format, knowing misrepresentation of payroll, or failing to keep required records carries substantial penalties.

These requirements suggest that for employees with tracked hours, reported hours provide a good measure of actual hours worked. For employees without tracked hours, in turn, reported hours may not reflect actual hours worked. But this only leads to mismeasurement of the change in the hourly wage rate as perceived by the firm if the difference between the reported 40 hours and actual hours varies and the firm tracks these variations but does not report them. ${ }^{22}$ Given the clear reporting instructions, this seems unlikely.

Of course, for both hourly paid and salaried workers, reported hours may differ from effective hours; i.e. hours as perceived by the firm plus hours "off the clock" times the effort per hour of work. But this should not be the concern here. Firms in many cases cannot directly observe or contract on effective hours but instead try to use their wage policy to manage the effort margin, either explicitly through performance pay schemes or implicitly by appealing to norms. ${ }^{23}$ The objective of the DNWR literature, including this paper, is to document the characteristics and consequences of such wage policies.

To investigate the quality of the hours data formally, we conduct several tests. First, we compute the distribution of hourly wage levels and find a large spike at the minimum hourly wage (which increases in all but one year of our sample) and essentially no mass below the minimum wage. We also find sizable spikes at integer wage rates above the minimum wage. This indicates that for hourly paid workers, reported hours are indeed an accurate measure of actual hours worked.

Second, we document how the distribution of the year-to-year change in average weekly hours varies by the level of hours reported. As shown in Panel (a) of Figure A.1, the

${ }^{21}$ The instructions are available at https://www.esd.wa.gov/employer-taxes/reporting-requirements. There are a number of instances for which employers are instructed to report zero hours, specifically for disbursements after the employment relationship with a worker has ended. We exclude these zero hours observations from our sample.

${ }^{22}$ To see this, remember that the change in the hourly wage rate is defined as $\Delta \ln \left(W_{i t}\right)=\Delta \ln \left(E_{i t}\right)-$ $\triangle \ln \left(H_{i t}\right)$. As long as the difference between hours reported $H_{i t}$ and actual hours worked remains constant, the change in the wage rate is not affected and, for untracked workers with constant reported 40 hours per week, simply reflects the change in earnings.

${ }^{23}$ This receives receives widespread support from the personnel economics literature (e.g. Lazaer and Shaw, 2007) and from behavioral economics (e.g. Fehr and Gächter, 2000). Wage norms are also identified as the key driver for DNWR by Bewley (1999) from his interviews with managers. 
distribution of weekly hours for job stayers has a peak of about $23 \%$ at 40 hours and $55 \%$ of the mass is located between 35 and 43 hours. The peak at 40 hours is only about half as large as the fraction of salaried workers in the CPS, suggesting that employers in Washington track hours for a substantial portion of salaried workers. ${ }^{24}$ As Panel (b) of Figure A.1 shows, full-time workers (35 hours of work or more per week) are much more likely to have a zero or small change than part time workers (less than 35 hours of work per week). Moreover, the majority of zero hours changes in the 35-40 hours group come from workers with exactly 40 hours of work. ${ }^{25}$ This implies that employers indeed report consistently 40 hours for employees without tracked hours.

Third, we assess the signal-to-noise ratio in hours changes by running predictive regressions. As discussed in the next section, job-stayer level regressions of changes in hours on changes in earnings imply large and highly significant coefficients. Further, we find in firmlevel regressions that differences in firm and industry characteristics can account for almost $70 \%$ of the variation in the proportion of job stayers with zero hours change across firms. Both of these results indicate that the extent of mismeasurement of hours as perceived by the firm is unlikely to be an important issue - a conclusion that is confirmed with similar tests by Lachowska et al. (2018).

\subsection{Sample characteristics and representativeness}

We consider two samples in our analysis. The first consists of all job stayers employed in private non-farm firms in Washington between 1998 and 2013 and is used to document the extent of DNWR in Section 3. The second consists of job stayers between 2004 and 2013 employed by firms with at least 50 job stayers over the period 2004-2007 and is used for the firm regressions in Section 4. These restrictions are necessary to have well-defined wage change distributions for the identification of DNWR at the firm level and to reduce sample attrition. $^{26}$ The job stayer sample contains 14.5 million job stayer - year observations or

\footnotetext{
${ }^{24}$ The low proportion of workers with 40 hours per week should not come as a surprise. All salaried workers legally eligible for overtime pay (non-exempt under the Fair Labor Standards Act) must have their hours tracked. To be exempt under FLSA, positions must exceed a salary threshold and duties performed must be relatively high level managerial, professional, and administrative duties. Many companies also choose to track hours for salaried workers to bill clients. And some companies track hours for salaried workers because they offer overtime pay as an additional incentive. For example, in 2016, Boeing announced it was eliminating overtime pay for exempt employees as a cost-cutting measure (see CNBC, 2016).

${ }^{25}$ The proportion of zero hours changes for workers with 40 hours is so large that disclosure avoidance rules prevent us from reporting them separately.

${ }^{26}$ The firm regressions require us to follow firms over time. Attrition of firm SEINs can arise either because of firm death or SEIN changes due to reorganization or mergers and acquisitions.
} 
about 1 million observations per year. The firm sample contains about 7 million job stayer observations or about 800,000 observations per year. This is orders of magnitude larger than the sample sizes available from survey-based data sources for the U.S.

Table 1: Washington State sample characteristics

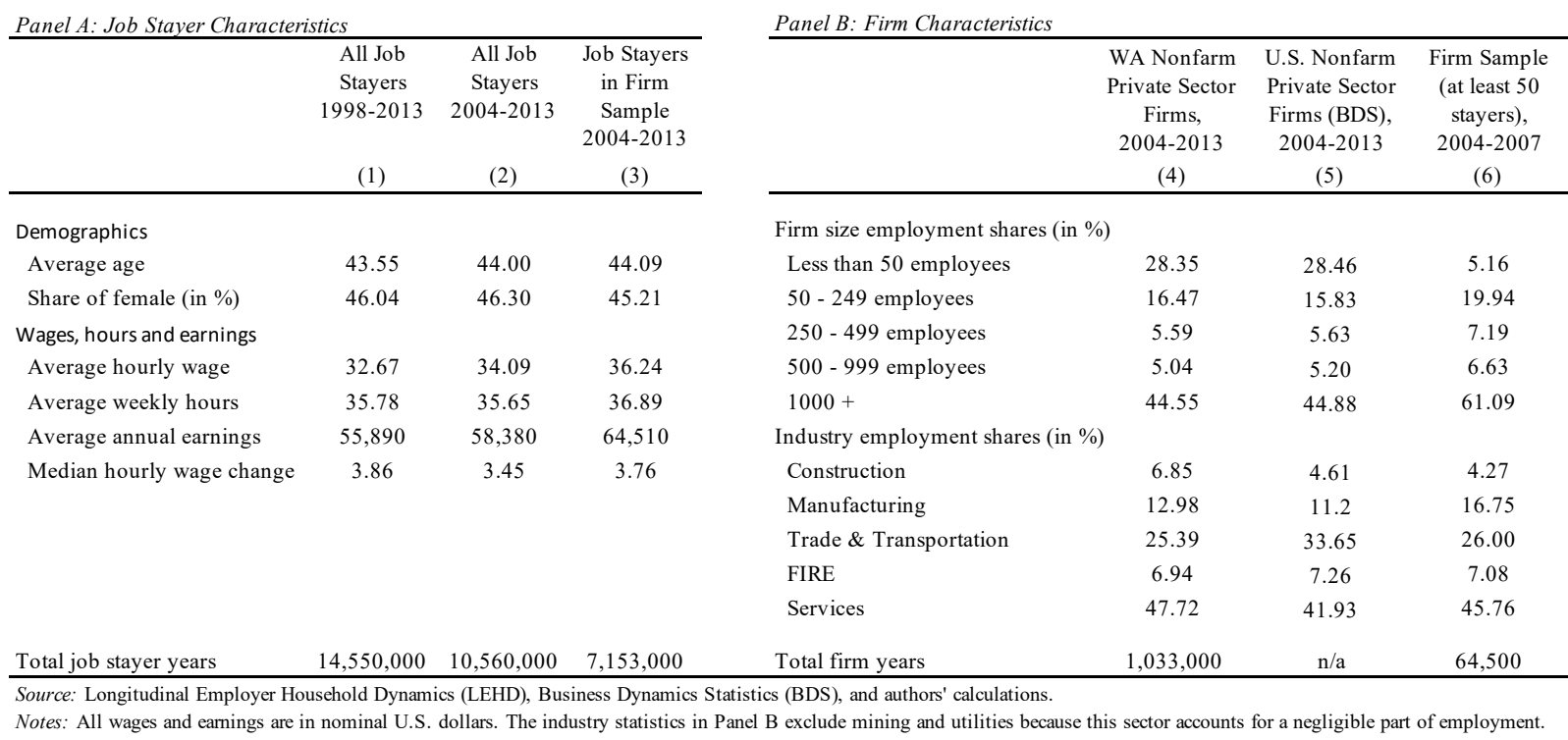

Panel A of Table 1 reports average characteristics of job stayers in the two samples. Average age and proportion of female job stayers are very similar across the two samples and line up closely with the age and gender characteristics reported for the larger 30 state sample in Kurmann et al. (2016) (see Sample 2 in Table 1). Average hourly wage, average weekly hours and average annual earnings are slightly lower in the job stayer sample (columns 1 and 2) than in the firm sample (column 3), reflecting that the firm sample is composed of larger firms that pay higher wages and hire more full-time workers. Compared to average wages and earnings across the entire U.S. workforce, these numbers are noticeably higher. This is not surprising since we consider only job stayers - i.e. workers with at least 10 continuous quarters of employment in the same firm - who are more skilled and earn higher compensation on average than workers employed for shorter periods of time.

Panel B of Table 1 provides information on the size and industry distributions of firms in the two samples and compares them to national averages from the publicly available Business Dynamics Statistics (BDS) of the U.S. Census Bureau. The size distribution of the job stayer sample (column 4), which includes all firms, is almost identical to the average size distribution for the U.S. (column 5), and the industry distribution is also quite close. The size distribution of the firm sample (column 6) naturally skews towards larger firms since this 
sample only includes firms with at least 50 job stayers over the 2004-07 period. Similarly, industries with a higher share of large firms such as manufacturing receive a somewhat larger weight. These differences are modest, however.

As shown in the appendix, Washington also exhibits aggregate business cycle movements that share the same timing and magnitude relative to the U.S. as a whole. We therefore conclude that Washington is quite a nationally representative state both in terms of firm characteristics and business cycle fluctuations. This suggests that the findings below apply for the U.S. labor market more broadly.

\section{Extent of Downward Nominal Wage Rigidity}

We begin by documenting key characteristics of the wage and earnings change distribution of job stayers in our LEHD data. Following the literature, we report many results nonparametrically through histograms. ${ }^{27}$ To further characterize the distributions, we consider three indicators: (i) proportion of zero changes (ii) excess zero spike defined as the mass of zero changes relative to what a symmetric distribution predicts; and (iii) missing mass left of zero defined as the proportion of cuts relative to what a symmetric distribution predicts. ${ }^{28}$ These indicators are closely related to asymmetry measures that the literature has associated with DNWR; e.g. Card and Hyslop (1997), Kahn (1997) or Lebow et al. (2003). It is important to emphasize that while these indicators may be suggestive of constraints in the wage setting process, they measure first and foremost the extent of DNWR in a statistical sense. $^{29}$ Even so, the indicators are useful to characterize variations in wage change distributions over time. Furthermore, in Section 4 we will exploit differences in these indicators across firms to test for allocative consequences of DNWR.

As additional statistics, we consider the dispersion between the $25^{\text {th }}$ and the $75^{\text {th }}$ percentile of the different distributions, $P_{75}-P_{25}$, as well as Kelley's skewness, which is defined as $1-2 *\left(P_{50}-P_{10}\right) /\left(P_{90}-P_{10}\right)$. Dispersion is an inverse measure of wage growth compression

\footnotetext{
${ }^{27}$ As in most survey-based studies, our histograms show log differences grouped in $1 \%$ bins centered around zero. Specifically, the zero bin contains all log changes between -0.005 and 0.005 , which approximately corresponds to changes between -0.5 and $0.5 \%$; the adjacent intervals contain observations in between -0.015 and -0.005 , respectively 0.005 and 0.015 ; and so forth.

${ }^{28}$ Formally, if $F(\cdot)$ is the cumulative density, the proportion of zeros is $F(0.005)-F(-0.005)$; excess zero spike is $[F(0.005)-F(-0.005)]+\left[F\left(2 P_{50}+0.005\right)-F\left(2 P_{50}-0.005\right)\right]$; and missing mass left of zero is $1-F\left(2 P_{50}+0.005\right)-F(-0.005)$, where $P_{50}$ denotes the median.

${ }^{29}$ For instance, even in the absence of constraints on wage setting, the wage change distribution of job stayers may be asymmetric because of non-linearities inherent in the wage setting process (e.g. preferences, technology) or asymmetries in the distribution of match-specific productivity growth.
} 
that, as Elsby (2009) argues, increases with the extent to which DNWR constraints bind. Kelley's skewness is a complementary measure of asymmetry that is positive if the mass of a distribution is more concentrated to the left of the median (or, equivalently, if the distribution has a longer right tail). This measure provides us with an interesting comparison to Guvenen et al. (2014) on the time-varying skewness of earnings changes in Social Security Administration (SSA) data.

\subsection{Hourly wage changes}

Figure 1 shows the distribution of four-quarter wage changes in our job stayer sample for two particular years: 2005-06, which represents an average year prior to the Great Recession; and 2009-10, which is characteristic of the wage change distribution in the aftermath of the Great Recession. ${ }^{30}$

Figure 1: Hourly wage change distribution, 2005-06 vs. 2009-10

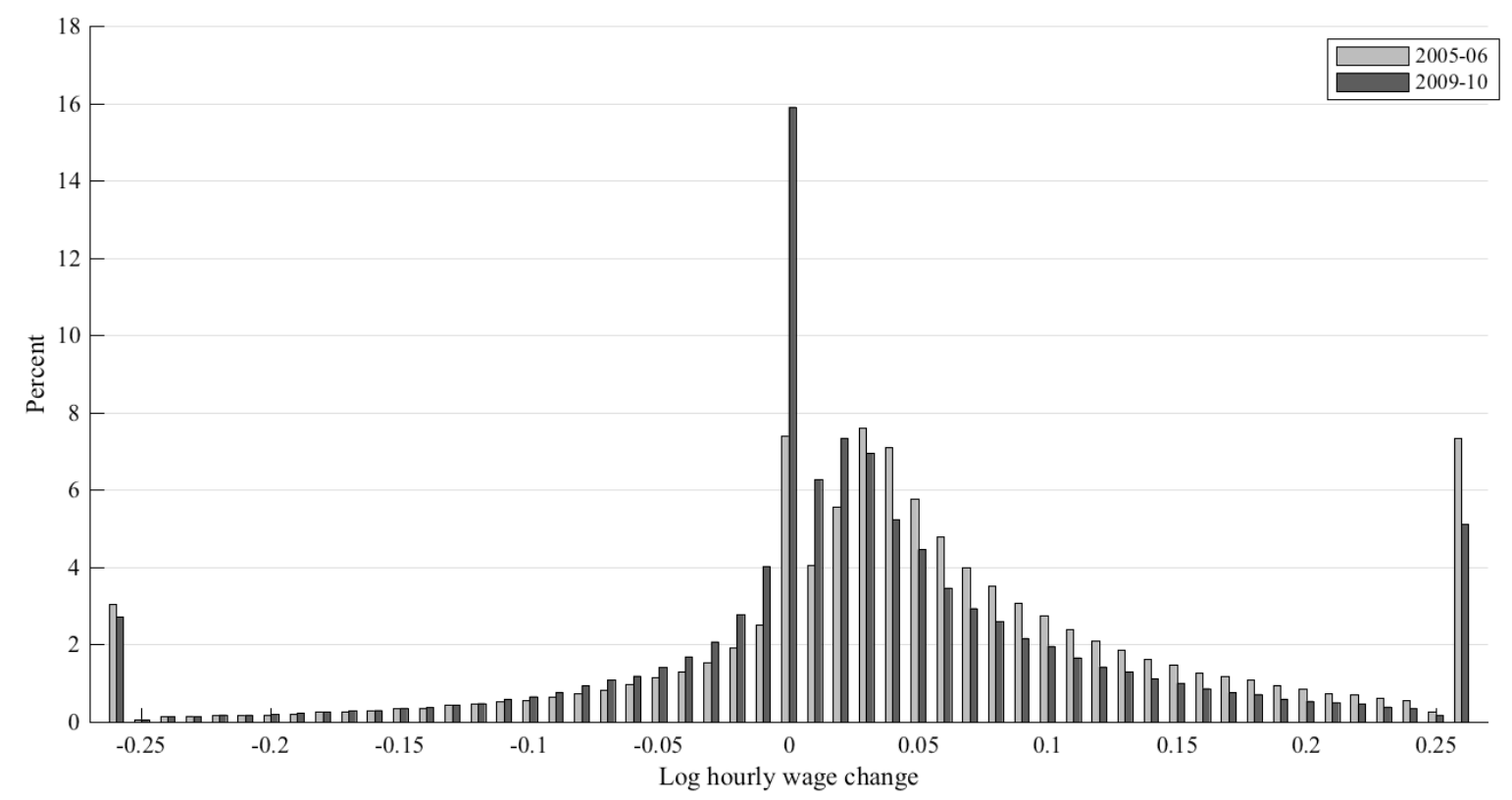

Notes: Washington state job stayer sample. Distributions of four-quarter log hourly wage changes for 2005:2-2006:2 and 2009:2-2010:2. The first and last bar of each histogram contain all observations smaller than -0.255 and observations exceeding 0.255 , respectively.

Three observations stand out. First, for 2005-06 the proportion of job stayers with a zero wage change amounts to only 7.5\% whereas for 2009-10 this proportion more than doubles to $16 \%$. Second, a large share of job stayers experiences a wage cut, totaling about $20 \%$ in 2005-06 and about 25\% in 2009-10. Third, for 2009-2010 the wage change distribution shifts

\footnotetext{
${ }^{30}$ The distribution of four-quarter wage changes pooled over all available years is reported in Figure A.3.
} 
noticeably to the left and becomes more concentrated, containing fewer large wage increases but more small wage cuts and small wage raises.

Figure 2 provides further insights into how the wage change distribution varies over time. As Panel (a) shows, both the median and the $75^{\text {th }}$ percentile decline markedly during both the 2001 recession and the Great Recession, recovering only slowly thereafter. The $25^{\text {th }}$ percentile remains steady during the 2001 recession but declines between 2008 and 2009 when the share of job stayers receiving wage cuts rises to $30 \%$. Since this decline is smaller than the decline of the $75^{\text {th }}$ percentile, there is persistent compression from the top, as evidenced by the time path of the $75-25$ dispersion.

Figure 2: Variations of hourly wage change distribution over time
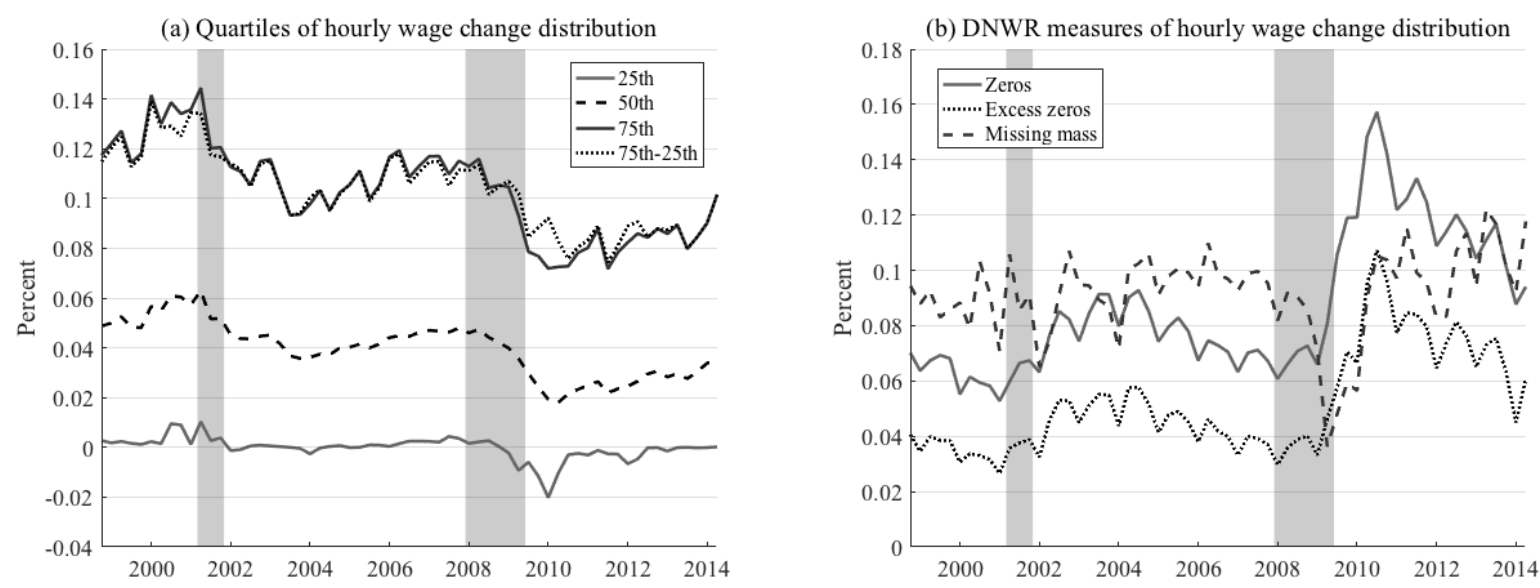

Notes: Washington state job stayer sample. The different statistics pertain to four-quarter log hourly wage change distributions from 1998:3 to 2014:1. Grey bars show NBER recession dates. For confidentiality purposes, the percentiles reported in Panel (a) are fuzzed by taking a 5-percentile average around the percentile of interest (e.g. the reported medians are averages of the $48^{t h}, 49^{t h}, 50^{t h}, 51^{s t}$, and $52^{\text {nd }}$ percentiles).

Panel (b) displays the evolution of the different DNWR indicators over time. The indicators exhibit considerable seasonality which, as we discuss below, is suggestive of variable pay components that are disbursed primarily at the end of the year. During the Great Recession, the proportion of zero wage changes and the excess zero spike hold relatively steady through early 2009 before increasing strongly until the third quarter of 2010. A similarly delayed yet substantially smaller increase in these two measures occurs for the 2001 recession. Missing mass left of zero, in turn, declines sharply from mid-2008 to mid-2009 before recovering to its pre-recession level by mid-2010. As shown in Figure A.4 in the appendix, Kelley's Skewness also drops sharply from about $20 \%$ in the beginning of 2008 to $0 \%$ by the end of 2009 before increasing back to its pre-recession level by mid-2010. Both of these statistics indicate that the wage change distribution becomes more symmetric during the Great Recession. 
The results in Figures 1 and 2 have important implications for business cycle theories based on nominal wage rigidities. First, the fact that wage cuts are far from a rare occurrence contradicts the premise of a strongly binding DNWR constraint maintained in many Keynesian explanations of recessions as well as a number of prominent recent dynamic general equilibrium models. ${ }^{31}$ More generally, the small proportion of zero wage changes represents a challenge for New Keynesian models, which do not impose DNWR per se but typically require a much larger degree of nominal wage stickiness to generate business cycle fluctuations in line with the data. ${ }^{32}$ Second, while our results provide some evidence of DNWR during the pre-recession period in the sense that the wage change distribution is asymmetric and features a modest spike at zero, these indicators of DNWR move in opposite directions during the Great Recession and its aftermath. This seems hard to square with models in which DNWR is imposed exogenously as is done in much of the literature. ${ }^{33}$ Likewise, the increase in the proportion of zeros as the economy stabilizes seems inconsistent with time-dependent wage reoptimization as assumed in most New Keynesian models as well as s-S type models of state-dependent wage adjustment (as is popular for price setting) because such models would predict that the proportion of zeros in response to a large negative shock declines.

The presented evidence also differs substantially from previous results based on U.S. household survey data. For instance, Daly and Hobijn (2014) and Elsby et al. (2016) use CPS data for a similar time period as us and find a proportion of zero wage changes between $10 \%$ and $18 \%$ prior to the Great Recession despite the fact that their wage change distribution is otherwise more dispersed. ${ }^{34}$ And while both of these studies note an increase in the proportion of zeros as the economy starts to recover, the magnitude of this increase is more

\footnotetext{
${ }^{31}$ See for example Kim and Ruge-Murcia (2009); Schmitt-Grohe and Uribe (2013; 2016; 2017), Eggertsson and Mehrotra (2015), Auclert and Rognlie (2016) and Dupraz et al. (2016).

${ }^{32}$ As discussed in the introduction, when viewed through the lens of a canonical Calvo model of wage setting, our pre-recession estimate of $7-8 \%$ of zero wage changes implies an adjustment probability of about 0.45 per quarter, much higher than what for example Christiano et al. (2005) or Smets and Wouters (2007) estimate for their models to fit macroeconomic data.

${ }^{33}$ See Benigno and Ricci (2011); Abbritti and Fahr (2013) or Daly and Hobijn (2014) for models in which DNWR is imposed on only a fraction of workers. These models can generate an increase in the proportion of zero wage changes if inflation declines during a recession, but they cannot generate first an increase in the frequency of wage cuts and a more symmetric wage change distribution that is followed by a delayed increase in the proportion of zero wage changes as we observe in our data.

${ }^{34}$ Also see the Wage Rigidity Meter website maintained by the Federal Reserve Bank of San Francisco, which updates the results in Daly and Hobijn (2014). For the results by Elsby et al. (2016) note that their histograms pertain to $0.02 \mathrm{log}$ change bins, which makes the wage change distributions appear more concentrated than it would be for $0.01 \mathrm{log}$ change bins. Other studies with U.S. survey data that do not correct for measurement error report similarly high or higher proportions of zero wage changes. See for example Kahn (1997) or Dickens et al. (2007) for results based on PSID data; and Gottschalk (2005) for results based on SIPP data.
} 
than double in our data - almost 9\% - primarily because the proportion of zeros is so low in the pre-recession period. Even more striking is the contrast with studies such as Akerlof et al. (1996), Altonji and Devereux (2000), Gottschalk (2005) or Barratieri et al. (2014) who argue that the incidence of wage cuts in household survey data is substantially overstated due to measurement error and that once one corrects for these errors, the proportion of zero wage changes rises as high as $50 \%$ whereas wage cuts become the exception.

What explains this discrepancy in results? Measurement error in household survey data certainly plays a role. Yet, as discussed by Elsby et al. (2016), measurement error does not only come in the form of classical reporting error, which indeed biases the proportion of zero wage changes downward and the occurrence of wage cuts upward, but also in the form of rounding error, which has exactly the opposite effect. Without further information, it is unclear what the relative importance of these two types of measurement error is and how to appropriately correct for them. ${ }^{35}$

The other source of discrepancy is that surveys such as the CPS only ask about regular or base pay whereas the LEHD earnings records include all compensation disbursed to workers, including bonuses, overtime pay, tips and commissions. While the LEHD only provides information on total compensation, a large literature on wage cyclicality indicates that compensation beyond base pay is important for wage adjustment (e.g. Shin and Solon, 2007) and therefore may also be a key driver behind our results. ${ }^{36}$ This is confirmed in ongoing work by Grigsby et al. (2018) who use administrative data from ADP for 2008-2016 that allows identification of different pay components. They find that reductions in base pay are indeed exceedingly rare for job stayers and that about $35 \%$ of job stayers have the same base pay than a year earlier. In contrast, non-base pay components are much more flexible - both upward and downward - which is consistent with our result in Panel (b) of Figure 2 that different DNWR indicators are systematically lower for wage changes pertaining to quarter four when many of the bonuses are disbursed. Once Grigsby et al. (2018) include bonuses as part of compensation, the proportion of pay cuts among non-commission job stayers increases to almost $16 \%$ and the proportion of zero changes drops to $13 \%$, even though bonuses account

\footnotetext{
${ }^{35}$ Evidence from the U.K. by Smith (2000) suggests that rounding error plays a more important role. For the U.S., there is no direct evidence on the effects of different types of measurement error on wage change distributions. Fallick et al. (2016) use firm survey data from the ECI, which is presumably less subject to measurement error, and find a more concentrated wage change distribution. At the same time, the proportion of zero wage changes prior to the Great Recession remains well in excess of $10 \%$.

${ }^{36}$ Also see Babecky et al. (2012) who analyze survey data from 12 European countries and find that firms frequently use margins other than changes in the base wage to adjust labor costs; or Altonji and Devereux (2000) who report in a study of personnel files of a large financial corporation that reduction in bonuses are quite common.
} 
for only a small fraction of total compensation for the average worker. ${ }^{37}$ Lastly, when they compute hourly wage changes in the same way as we do (i.e. for all job stayers and including all forms of compensation), the results become strikingly similar to ours, with 10-15\% of job stayers experiencing a zero wage change and 20-25\% experiencing a wage cut. ${ }^{38}$

Our results in combination with the findings by Grigsby et al. (2018) provide an intriguing new characterization of DNWR: while wages adjusts frequently both upward and downward once all forms of compensation are included, the extent of downward flexibility is limited by the fact that base wages are almost never cut and that non-base pay accounts on average for only a small part of total compensation. In other words, DNWR may still be a relevant constraint, just not one that is as absolute and exogenous as often assumed in the literature. This could explain why our wage change distribution prior to the Great Recession shows a relatively small proportion of zero wage changes but many small wage cuts and raises. The same characterization of DNWR would also rationalize why we observe a higher incidence of small wage cuts and a more symmetric wage change distribution during the Great Recession, followed by a substantially higher proportion of wage freezes as the economy starts to recover: since cuts in non-base pay provide only relatively small reductions in total compensation, they are compensated with a higher incidence of wage freezes and smaller raises later on.

\subsection{Wage change distribution by firm characteristics}

Next, we exploit the worker-firm link of the LEHD data to investigate whether the wage change distribution varies systematically by firm characteristics. We start with firm size and firm growth. As Figure 3 shows, there is a striking inverse relationship between firm size and the proportion of job stayers with wage freezes. The wage change distribution for small firms (less than 50 employees) exhibits a large spike at zero with about $14.5 \%$ of job stayers being paid the same hourly wage in 2005-06 as a year earlier whereas for large firms (500 employees or more), this proportion is only about $4 \%$ and there is no perceptible spike.

\footnotetext{
${ }^{37}$ Interestingly, when compensation is broadened further to include fringe benefits, the proportion of pay cuts increases to almost $19 \%$.

${ }^{38}$ See Panels B and C of Figure A8 in Grigsby et al.. These results pertain to their pooled wage change distribution for 2008-2016. When we start our sample in 2008, we obtain very similar results, providing further confirmation that Washington is representative of the U.S. labor market more broadly. Grigsby et al. focus primarily on base pay per contract period and annual base pay + bonuses, in part because the quality of the hours data in the ADP sample is unknown. As discussed in the introduction, if hours vary, then variations in annual base pay + bonuses do not accurately reflect variations in average hourly wages - the main metric in the DNWR literature. Controlling for variations in hours is even more important for other forms of non-base pay such as commissions and overtime pay (both of which are excluded in Grigsby et al.'s main measures of wage rigidity) because they are more directly linked to hours worked.
} 
Like in the aggregate, the proportion of zero wage changes increases substantially for both size categories as the economy starts to recover from the Great Recession, reaching $26.5 \%$ in 2009-10 for small firms and about $10 \%$ for large firms. ${ }^{39}$

Figure 3: Hourly wage changes of job stayers by firm size, 2005-06 vs. 2009-10
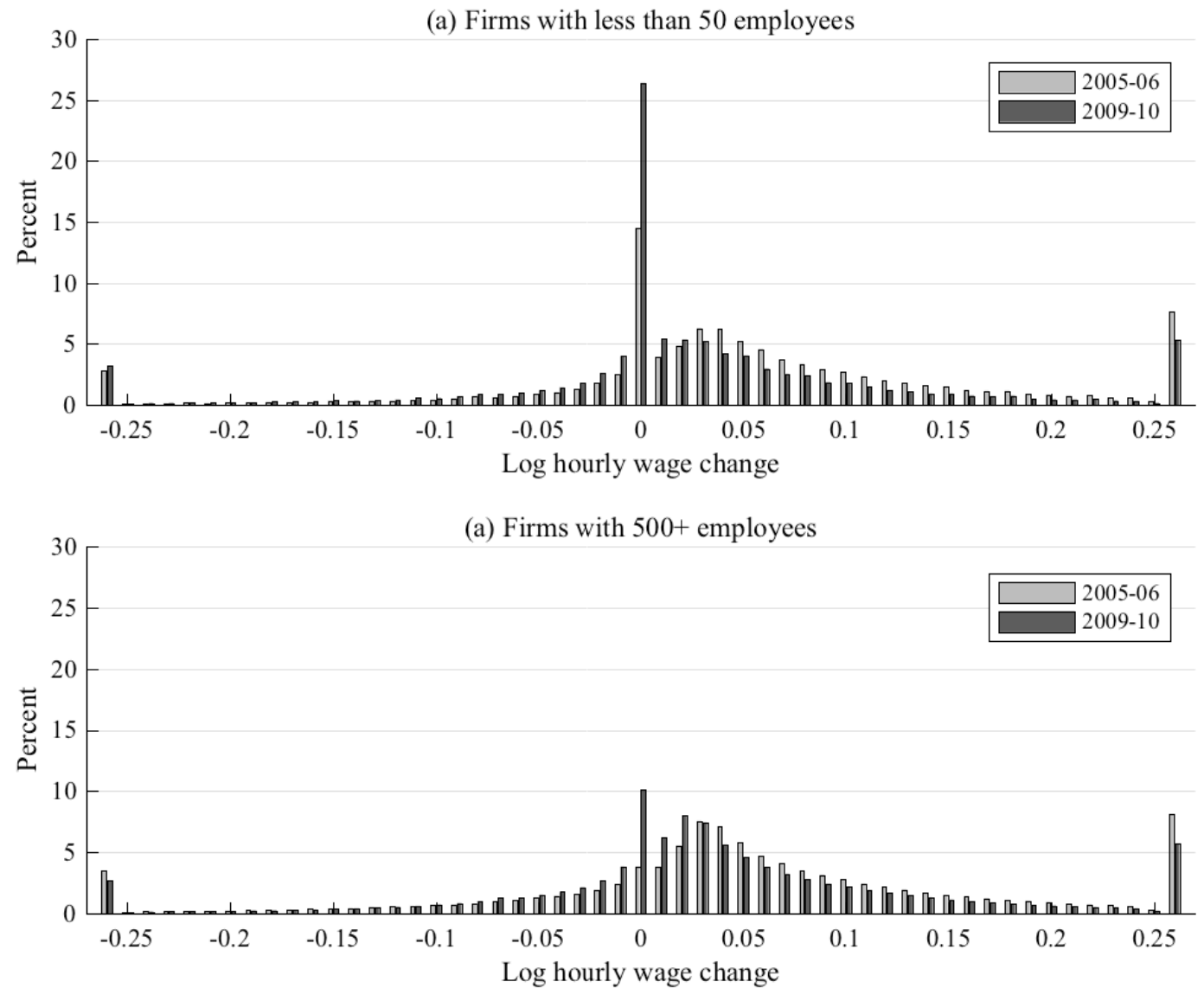

Notes: Washington state job stayer sample. Distributions of log hourly wage changes for 2005:2-2006:2 and 2009:2-2010:2. The first and last bar of each histogram contain all observations smaller than -0.255 and observations exceeding 0.255 , respectively.

Interestingly, the larger proportion of wage freezes in small firms is accompanied by both fewer small wage cuts and fewer small wage raises than in large firms. One explanation for this result could be that small firms are on average more volatile than large firms, but this would make the larger proportion of zeros all the more striking. Another possibility is that small firms make less use of variable forms of payment than large firms because the fixed cost of implementing such policies is prohibitive or because small firm size is more conducive to implicit contracting that provide at least partial insurance against wage cuts.

As Figure 4 shows, there is also a noticeable inverse relationship between firm growth

\footnotetext{
${ }^{39}$ The wage change distribution for mid-size firms (50-499 employees) is in-between the distributions for small and large firms, with a proportion of zero wage changes of $7 \%$ in $2005-06$ and $16 \%$ in $2009-10$.
} 
and proportion of job stayers with wage freezes. In contracting firms with employment growth of less than $-10 \%$, there are about $1 \%$ more job stayers who in 2005-06 are paid the same hourly wage as one year earlier than in expanding firms with employment growth of more than $+10 \% .{ }^{40}$ At the same time, the wage change distribution of contracting firms contains a noticeably larger proportion of wage cuts than the distribution of expanding firms. This difference in distributions is qualitatively similar to the difference in the aggregate distribution before and during the Great Recession although quantitatively, the difference here is substantially less pronounced. This suggests that the Great Recession was particular in the sense that it led to larger wage changes than firm-level shocks prior to the Great Recession that were of comparable severity in terms of employment reaction.

Figure 4: Hourly wage changes of job stayers by firm growth, 2005-06

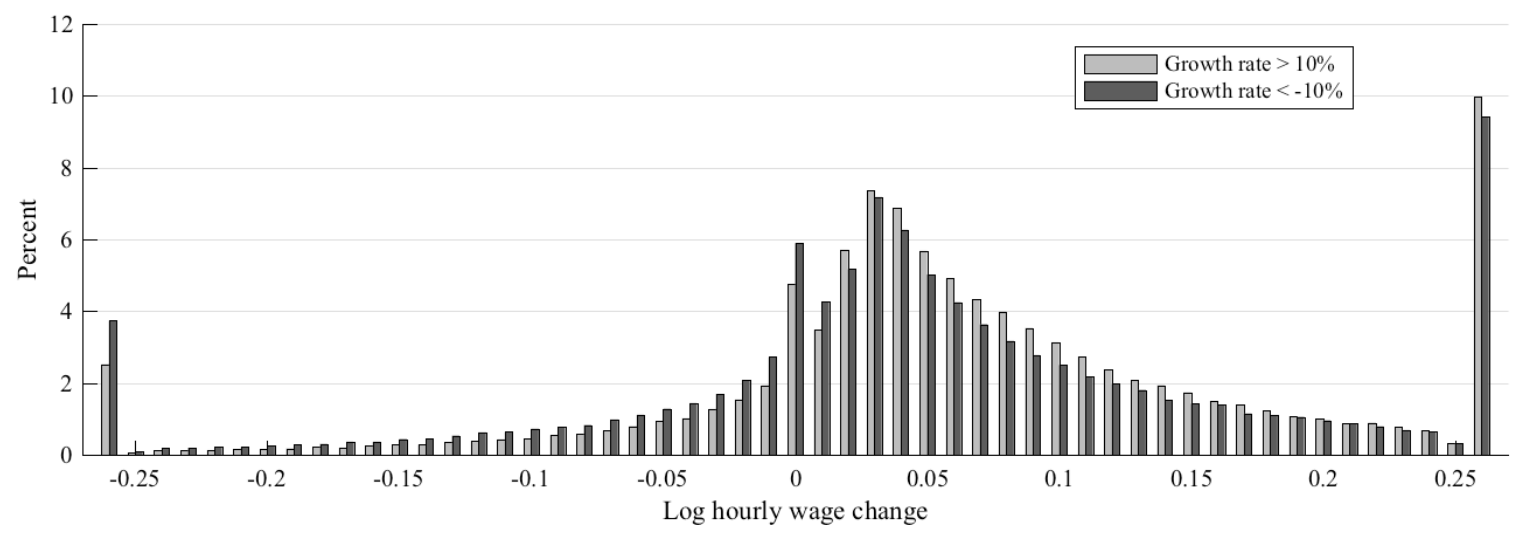

Washington state job stayer sample for firms with more than 30 employees in 2005-06. Distributions of four-quarter log hourly wage changes for 2005:2-2006:2. The first and last bar of each histogram contain all observations smaller than -0.255 and observations exceeding 0.255 , respectively.

To provide a more general analysis of how the wage change distribution varies by firm characteristics, we estimate a set of predictive regressions of the form

$$
z_{j}=\alpha+\mathbf{X}_{j}^{\prime} \beta+\epsilon_{j}
$$

where $z_{j}$ is one of the above distributional statistics for firm $j ; \mathbf{X}_{j}^{\prime}$ is a vector consisting of firm size indicators, the firm median wage change, different firm average worker characteristics, and two-digit NAICS industry indicators; and $\epsilon_{j}$ is an error term. To ensure that the distributional statistics are well defined at the firm level, we switch to the firm sample, which

\footnotetext{
${ }^{40}$ The figure is based on firms with at least 30 employees in 2005-06 because smaller firms often have very large and noisy employment growth rates that would have made categorizing firms into high and low growth groups meaningless. As a result of the selection on larger firms, the wage change distributions contain fewer zeros than what is observed in full job-stayer sample of the previous figures.
} 
consists of firms with at least 50 job stayers, and run these regressions as a simple panel for the 2004-2007 period since the above results indicate that the wage change distribution during the Great Recession and its aftermath is very different from the average.

Table 2: Characteristics of distributional statistics, 2004-2007

Dependent variables: various measures of Downward Nominal Wage Rigidity at the firm level, 2004-2007

\begin{tabular}{|c|c|c|c|c|}
\hline & $\begin{array}{c}\text { Mass of Zero } \\
\text { Wage Changes } \\
\text { (1) }\end{array}$ & $\begin{array}{l}\text { Excess Zero } \\
\text { Spike } \\
\text { (2) }\end{array}$ & $\begin{array}{c}\text { Excess Zero } \\
\text { Spike Indicator } \\
\text { (3) }\end{array}$ & $\begin{array}{c}\text { Missing Mass } \\
\text { of Wage Cuts } \\
\text { (4) }\end{array}$ \\
\hline Firm $<50$ employees & $\begin{array}{c}3.90 * * * \\
(0.24)\end{array}$ & $\begin{array}{c}3.39 * * * \\
(0.18)\end{array}$ & $\begin{array}{l}-0.04 \\
(0.04)\end{array}$ & $\begin{array}{c}1.87 * * * \\
(0.46)\end{array}$ \\
\hline Firm 50-249 employees & $\begin{array}{c}2.13 * * * \\
(0.20)\end{array}$ & $\begin{array}{c}1.75 * * * \\
(0.15)\end{array}$ & $\begin{array}{l}-0.01 \\
(0.04)\end{array}$ & $\begin{array}{c}1.25 * * * \\
(0.45)\end{array}$ \\
\hline Firm 250-499 employees & $\begin{array}{c}1.00 * * * \\
(0.33)\end{array}$ & $\begin{array}{c}0.68 * * * \\
(0.20)\end{array}$ & $\begin{array}{l}-0.04 \\
(0.05)\end{array}$ & $\begin{array}{l}0.45 \\
(0.52)\end{array}$ \\
\hline Median firm wage change & $\begin{array}{c}-0.16 * * * \\
(0.06)\end{array}$ & $\begin{array}{c}-0.06 * * * \\
(0.02)\end{array}$ & $\begin{array}{l}0.00 \\
0.00\end{array}$ & $\begin{array}{l}0.05 \\
(0.06)\end{array}$ \\
\hline Share stayers female & $\begin{array}{l}0.00 \\
(0.01)\end{array}$ & $\begin{array}{l}0.00 \\
0.00\end{array}$ & $\begin{array}{c}-0.00 * * * \\
0.00\end{array}$ & $\begin{array}{c}0.04 * * * \\
\quad(0.01)\end{array}$ \\
\hline Share stayers $<35$ hours a week & $\begin{array}{l}0.01 \\
(0.01)\end{array}$ & $\begin{array}{l}0.00 \\
0.00\end{array}$ & $\begin{array}{l}0.00 \\
0.00\end{array}$ & $\begin{array}{c}-0.04 * * * \\
(0.01)\end{array}$ \\
\hline Average job stayer age & $\begin{array}{c}0.11 * * * \\
(0.02)\end{array}$ & $\begin{array}{c}0.05^{* * *} * \\
(0.02)\end{array}$ & $\begin{array}{l}0.01 \\
0.00\end{array}$ & $\begin{array}{c}-0.12 * * * \\
(0.05)\end{array}$ \\
\hline
\end{tabular}

Notes: Sample 2004-2007 of firms with at least 50 job stayers. All regressions include intercept, NAICS-2 industry dummies and are weighted by firm employment. Standard errors in parentheses are clustered at firm level.

*** Significant at the $1 \%$ level; ** Significant at the $5 \%$ level; * Significant at the $10 \%$ level

Table 2 reports the regression results. Before discussing specific estimates, it is important to note that the explanatory power of the different predictors remains modest, with $R^{2}$ coefficients that do not exceed 0.2 for any of the regressions. Hence, a lot of the heterogeneity in wage change distribution across firms remains unexplained. Similarly, closer inspection of the data reveals that there is also a lot of within-firm dispersion in wage changes, suggesting that individual firm-worker matches are subject to considerable idiosyncratic shocks. This heterogeneity in wage changes both between and within firms motivates our firm-level regressions in Section 4.

As the first three rows of the table show, the smaller the firm size the larger the proportion of zeros, the larger the excess zero spike, and the larger the missing mass left of zero. These estimates are highly significant and indicate that the striking differences in wage change 
distribution by firm size shown in Figure 3 are robust to controlling for average worker characteristics and industry indicators. As shown in column (3), however, there is no relation between firm size and the existence of an excess zero spike. In other words, smaller firms have wage change distributions with disproportionally large excess zero spikes but not a higher frequency of excess zero spikes.

The fourth row of the table shows that, consistent with Figure 4, higher firm median wage growth is associated with fewer zero wage changes and a smaller excess zero spike. This indicates that even prior to the Great Recession, wage rigidity is state-dependent. The result also illustrates a perhaps trivial but in our view under-appreciated point in the literature: even if firms are DNWR constrained, the extent to which the constraint binds depends inversely on the firm's growth situation.

The next three rows report the estimated effect of share of female job stayers, share of job stayers that work part-time (less than 35 hours per week), and average job stayer age. The only characteristic with a systematic significant effect on the firm's wage change distribution is average job stayer age, which proxies for job tenure. However, this effect is very modest, suggesting that none of these worker characteristics are major determinants of DNWR. We obtain similarly small and insignificant estimates for other firm-specific variables that are not included here, in particular the share of job stayers paid the minimum wage, average wage level of job stayers, and the relative labor productivity rank of the firm within its industry. ${ }^{41}$

To save on space, we relegate the estimated effects of industry affiliation to Table A.1 in the appendix. Relative to firms in professional services (the omitted category), firms in construction, wholesale and retail trade, real estate, administrative support, arts and entertainment, and accommodation and food services have wage change distributions with a significantly higher proportion of zero wage changes and more missing mass left of zero. Exactly the opposite is the case for firms in finance and insurance, consistent with the notion that workers in these industries receive a relatively large part of their compensation in the form of bonuses and other variable pay components.

As with firm size, wage growth and the other predictors in Table 2, almost none of the industry indicators has a significant effect on the excess zero spike indicator. This makes the excess zero spike indicator our preferred measure of DNWR in the firm-level regressions of Section 4 since, as explained below, we want to separate our measure of DNWR as much as possible from other firm characteristics that could confound inference.

\footnotetext{
${ }^{41}$ Of course, it would also be interesting to see whether there is any relation between the different distributional statistics and variables such as education, union status or occupation. Unfortunately, the LEHD data does not contain this information.
} 


\subsection{Earnings changes and the importance of hours variations}

Although most of the existing DNWR literature focuses on hourly wage changes of job stayers, changes in total earnings are also relevant. Worker resistance to wage cuts is often cited as the source of DNWR. But we might expect workers to be similarly resistant to reductions in earnings. Moreover, labor cost can be adjusted not only through wage cuts but also through reductions in hours or temporary furloughs. Hence, the ability to reduce paid hours in response to a negative shock may be as important for employment dynamics as the ability to cut hourly wage rates.

Figure 5: Distribution of hours and earnings changes of job stayers
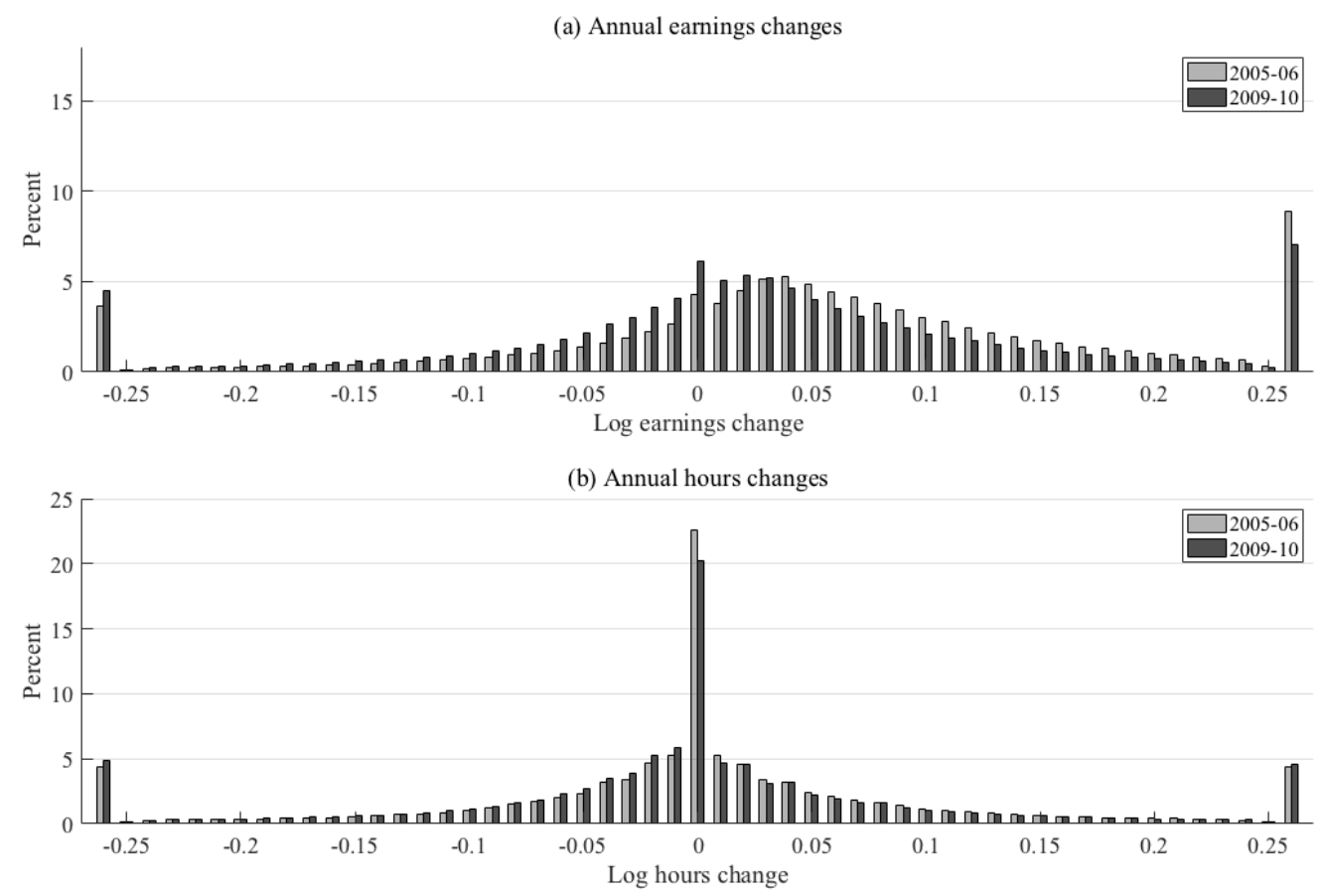

Notes: Washington state job stayer sample. Distributions of year-to-year log earnings and log hours changes for 2005-2006 and 2009-2010. The first and last bar of each histogram contain all observations smaller than -0.255 and observations exceeding 0.255 , respectively.

Figure 5 reports the distribution of earnings and hours changes for 2005-2006 and 20092010. Due to the pay-period problem described in Section 2, these distributions pertain to year-to-year changes instead of four-quarter changes. As Panel (a) shows, the distribution of earnings changes is considerably more dispersed than the distribution of hourly wage changes. $^{42}$ For 2005-2006, only about $4.5 \%$ of job stayers have the same earnings as a

\footnotetext{
${ }^{42}$ The corresponding distribution of year-to year changes in hourly wages has the same properties as in Figure 1 for four-quarter changes but is somewhat more disperse. This is unsurprising given that year-to-year changes include all wage changes over a two year period.
} 
year earlier and about $23 \%$ experience an earnings cut. For 2009-2010, the earnings change distribution shifts noticeably to the left, with the incidence of earnings cuts increasing to 34\%. At the same time, the proportion of job stayers with zero earnings change increases only modestly to about $6 \%$, much less than the proportion of job stayers with zero wage change.

The smaller share of zeros and the larger dispersion of earnings changes are due to variations in hours. As Panel (b) shows, about $23 \%$ of job stayers work the same hours in 2006 as in 2005. For the rest, hours changes are on average relatively small. ${ }^{43}$ For 2009-2010, the hours change distribution shifts left with a somewhat smaller proportion of job stayers with unchanged hours and a larger fraction experiencing a reduction in hours.

Figure 6: Variations in earnings and hours change distribution over time
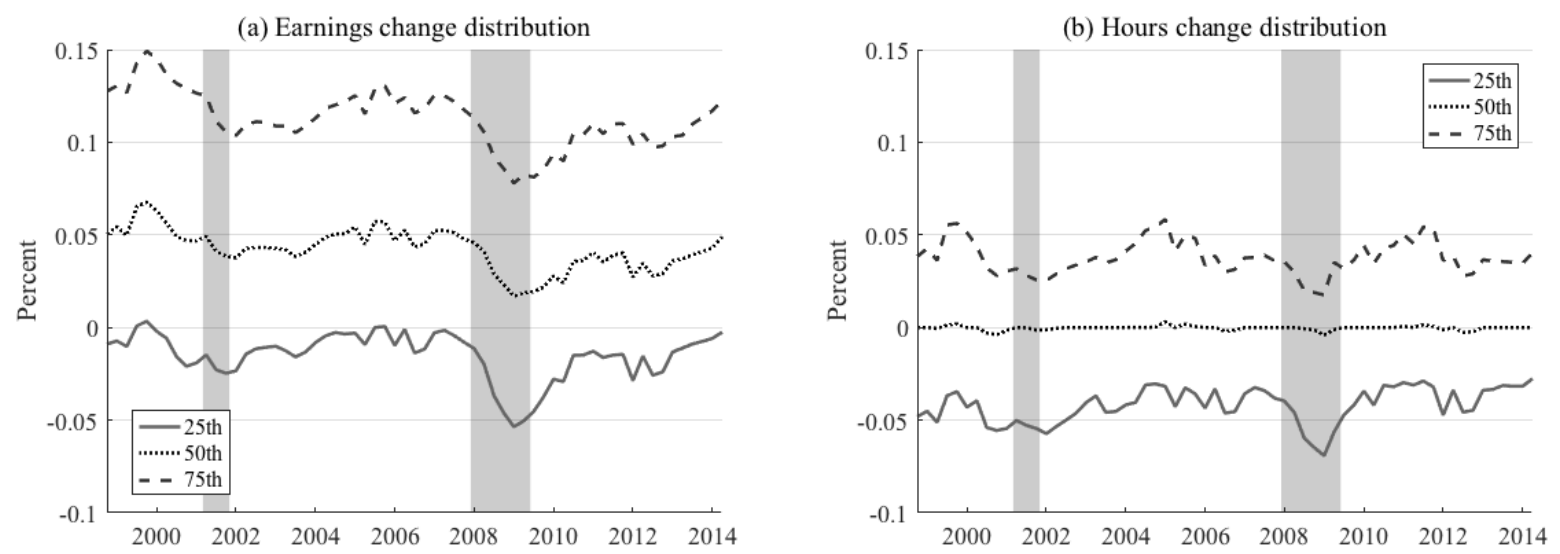

Notes: Washington state job stayer sample. The different statistics pertain to year-to-year log earnings and hours change distributions from 1998:3 to 2014:1. Grey bars denote NBER recession dates. For confidentiality purposes, the reported percentiles are fuzzed by taking a 5-percentile average around the percentile of interest (e.g. the reported medians are averages of the $48^{t h}, 49^{t h}, 50^{t h}, 51^{s t}$, and $52^{\text {nd }}$ percentiles).

Figure 6 provides additional evidence on the variations in earnings and the hours change distributions over time. As shown in Panel (a), the $25^{t h}$ percentile of the earnings distribution is consistently below zero and drops substantially between 2008 and 2009 with the share of job stayers receiving an earnings cut rising as high as 39\% - considerably more than the proportion of job stayers experiencing a wage cut during the Great Recession (see Figure 2). A similar result is obtained for the 2001 recession when the proportion of job stayers with earnings cuts declines whereas proportion of job stayers with wage cuts remains essentially constant. This implies that job stayers have higher downside earnings risk than indicated

\footnotetext{
${ }^{43}$ While part-time workers experience the largest fluctuations in hours worked, hours changes for full-time workers are also quite large, consistent with Borowczyk-Martins and Lalé (2018) who find that the decrease in hours per worker during downturns is driven primarily by transitions from full-time to part-time work at the same employer.
} 
by the distribution of hourly wage rates. Panel (b) confirms that this difference is driven by hours changes. During both the 2001 recession and the Great Recession, the hours change distributions shift to the left and the share of job stayers working fewer hours increases. As shown in Figure A.4 in the appendix, the decline in hours during recessions is also reflected in a strongly countercyclical skewness of the hours change distribution. This explains why the earnings change distribution, which exhibits mild positive skewness on average, becomes negatively skewed during the Great Recession even though the hourly wage change distribution shows no negative skewness during that time period. The results imply that a substantial part of the countercyclical earnings risk faced by job stayers, as documented by Guvenen et al. 2014 with SSA data, is due to the fact that job stayers work fewer hours during downturns. This has potentially important implications for the life-cycle consumption literature where earnings are often taken as an exogenous forcing process and the choice of hours is typically fixed or not disciplined due to the lack of availability of reliable hours data.

Figure 7: Earnings change decomposition. Washington State, 1998-2014

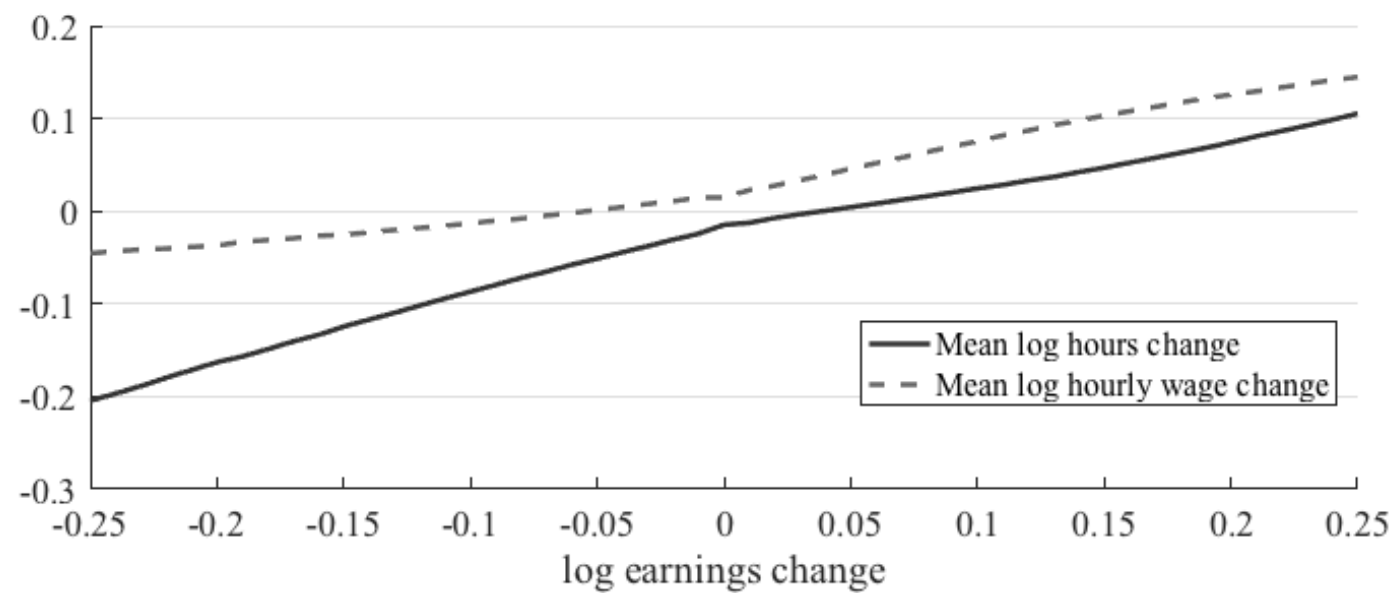

Notes: This graph decomposes the year-to-year log earnings change for every job stayer in the 1998-2014 job stayer sample into the corresponding log hourly wage change and the log hours change (i.e. $\Delta \ln E_{i t}=\Delta \ln W_{i t}+\Delta \ln H_{i t}$ ), and then averages the resulting hourly wage and hours changes for each $1 \%$ earnings change bin.

To explore the relationship between wage changes, hours changes and earnings changes further, we decompose the year-to-year earnings change for each job stayer into the corresponding hourly wage change and the hours change; i.e. $\Delta \ln E_{i t}=\Delta \ln W_{i t}+\Delta \ln H_{i t}$. The result of this decomposition, shown in Figure 7, is quite striking. For job stayers experiencing a reduction in earnings, on average about $75 \%$ is accounted for by fewer hours worked and about $25 \%$ is accounted for by cuts in the hourly wage. For job stayers experiencing an increase in earnings, by contrast, the split is roughly 50-50. In Table A.2 in the appendix, we confirm this result with regressions that control for demographic and firm characteristics 
as well as for full- versus part-time work status.

The results indicate that due to systematic variations in hours, earnings appear even less rigid than hourly wages and that variations in hours account for a larger part of earnings declines than wage cuts. These findings are suggestive of an allocative role of DNWR at the intensive (hours) margin: firms use hours to reduce labor costs in response to negative shocks because wages are more difficult to cut (or the extent to which they can be cut is limited). Concurrently, the observed results could also reflect labor supply choices made by workers although such an explanation seems at odds with recent evidence that a large part of cyclical swings in hours per worker are associated with transitions between full-time and involuntary part-time work at the same employer (see Borowczyk-Martins and Lalé, 2018).

\section{Consequences of Downward Nominal Wage Rigidity}

The previous section showed that even after controlling for a rich set of firm characteristics, large differences in DNWR indicators remain across firms. Viewed through the lens of the DNWR literature, these differences suggest that some firms pursue more downward rigid wage policies than others, thus making them more vulnerable to unexpected negative shocks. ${ }^{44}$ Yet, as highlighted in the introduction, an alternative interpretation is that the observed differences in wage change distributions are the result of variations in wage setting protocols between firms and workers in long-term employment relationships that do not necessarily play an allocative role. We now exploit the worker-firm link of the LEHD data to assess the two competing views.

This investigation comes with several potential challenges. First, a firm's wage change distribution used to construct the different indicators of DNWR is endogenous and depends not only on possible wage setting constraints but also on the extent to which such constraints bind. ${ }^{45}$ Second, firms with indicators of DNWR may be systematically different from less constrained firms along other dimensions that affect employment dynamics. For instance, DNWR firms may be disproportionally located in industries that decline for reasons other than downward wage rigidity. Similarly, better run firms may adopt not only more flexible wage setting policies but also take decisions that independently lead to higher employment

\footnotetext{
${ }^{44}$ The literature offers different explanations for the occurrence of DNWR. See for example the discussion in Bewley (1999). But to our knowledge, the literature has not explicitly discussed why some firms may be more subject to DNWR than others. Consistent with results from the previous section, one explanation is that some firms find it optimal to invest less in flexible non-base pay compensation than others.

${ }^{45}$ As suggested by the results in the previous section, the higher a firm's productivity growth, the more likely it is that workers receive a raise and thus, the less likely it is that DNWR constraints bind.
} 
growth. Third, as demonstrated by Elsby (2009), DNWR-constrained firms have an incentive to respond to positive productivity shocks with smaller wage increases so as to make it less likely that DNWR constraints bind in the future. It is therefore unclear whether all else equal, DNWR-constrained firms exhibit on average lower employment growth. ${ }^{46}$

Our strategy to address these challenges is as follows. We measure indicators of DNWR at the firm level for the 2004-07 period and estimate the effect on firm employment dynamics in response to the Great Recession - a large unexpected negative shock for which DNWR-constrained firms are unlikely to have prepared in advance. All else equal, employment of firms with indicators of DNWR should therefore be more sensitive to the Great Recession shock than employment of less constrained firms if these indicators indeed capture constraints in wage setting. Furthermore, we control for endogeneity of a firm's wage change distribution and possible confounds with a host of firm-specific observables, firm fixed effects, and industry-level shocks. Finally, we use the excess zero spike indicator as our preferred measure of DNWR (and test for robustness with respect to other measures later on) because, as discussed above, the excess zero spike indicator is not significantly predicted by firm-specific characteristics.

\subsection{Illustration of main result}

We start by illustrating the main result of this section through two simple figures that compare the employment dynamics of firms with an excess zero spike in their wage change distribution during 2004-07 - called "DNWR firms" from hereon - with firms without an excess zero spike - called "non-DNWR firms". Of the 64,500 firm-year observations in our sample, 43,500 or about two thirds fall into the DNWR category.

Figure 8 shows average employment dynamics for DNWR firms and non-DNWR firms. As demonstrated in Panel (a), the two types of firms have essentially the same average net employment growth rate over the pre-recession years and, unsurprisingly, both experience a large decline in employment growth during the Great Recession. However, the decline is substantially larger for DNWR firms, averaging $-3.2 \%$ for 2008 , and $-5.9 \%$ for 2009 . In

\footnotetext{
${ }^{46}$ Elsby derives the wage compression effect in a dynamic efficiency wage model in which worker effort depends negatively on nominal wage cuts. This assumption endogenously leads to a wage change distribution that exhibits DNWR and, since expected future payoffs are decreasing in today's wage, provides firms with an incentive to compress wage increases in response to positive productivity shocks. Earlier versions of the paper included an extended version of Elsby's model with endogenous hiring and separation, which establishes that firms in this environment also have a higher productivity threshold for hiring. Both the wage compression and the higher average productivity of workers counteract the negative effects of the effort constraint and imply that average employment growth remains essentially unaffected. The model is omitted from this version of the paper to save on space but is available upon request.
} 
comparison, average employment growth of non-DNWR firms drops to only $-0.46 \%$ for 2008 and then to $-5.0 \%$ in 2009. In the aftermath of the recession, employment growth recovers but remains anemic for both groups, averaging 1.17\% for DNWR firms and $0.97 \%$ for nonDNWR firms for the 2010-12 period. As shown in Panel (b), this implies that the level of employment falls by about 3\% more for DNWR firms during the Great Recession and remains substantially further below its 2007 peak through 2012 than for non-DNWR firms.

Figure 8: Employment dynamics of DNWR vs. non-DNWR firms
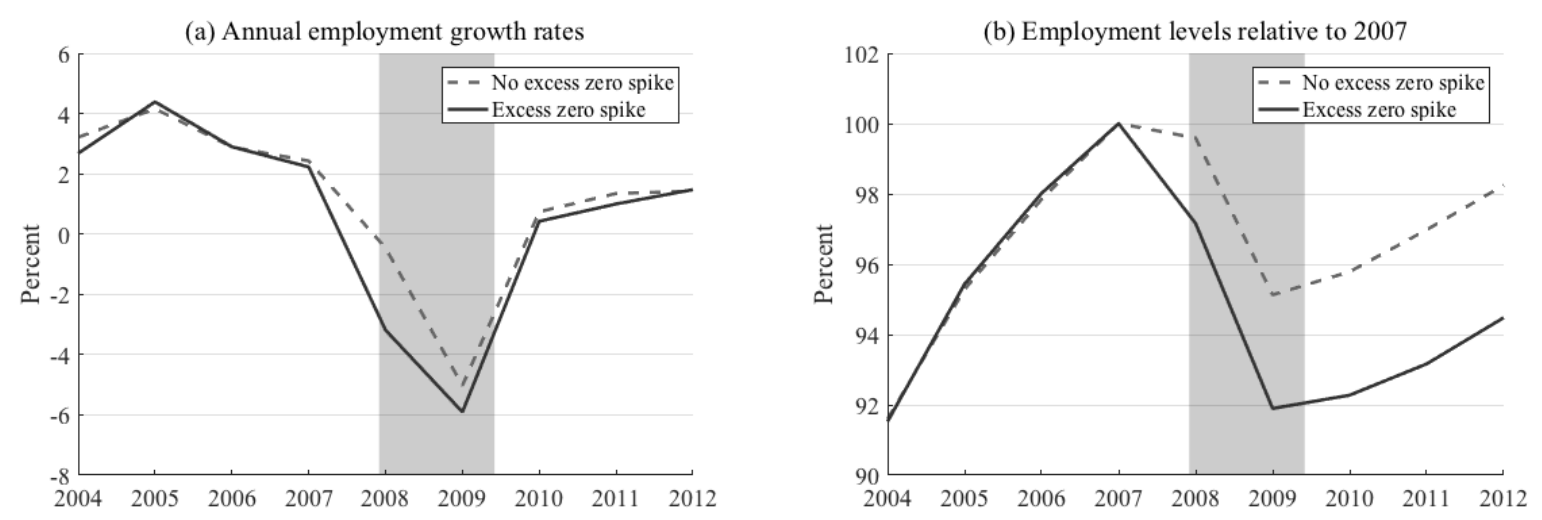

Notes: Washington state firm sample. The left graph shows average annual employment growth rates of firms with and without an excess zero spike in their wage change distribution during 2004-07. The right graph cumulates these growth rates over time and normalizes the resulting series to 100 in 2007.

Figure 9 digs deeper by comparing the distribution of annual employment growth across DNWR and non-DNWR firms for the pre-recession period and the Great Recession period.

Figure 9: Employment growth distributions of DNWR vs. non-DNWR firms
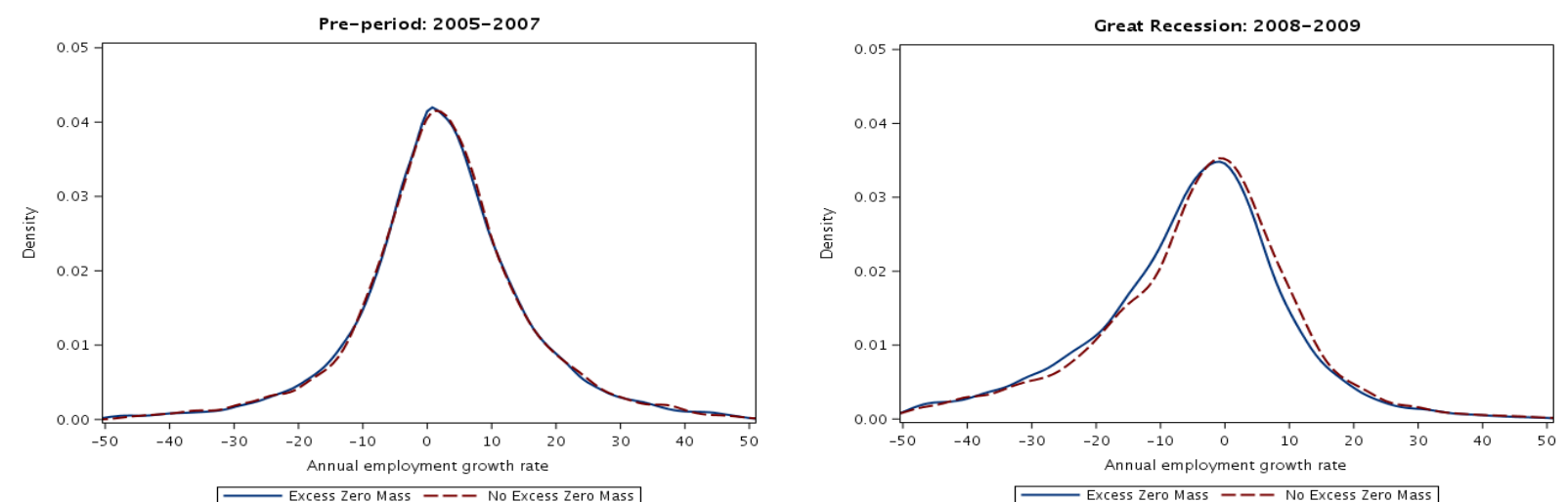

Notes: Washington state firm sample. The left graph shows pooled employment growth rates for 2004-2005, 2005-2006 and 2006-2007 for firms with and without an excess zero spike in their wage change distribution during 2004-07. The right graph shows the pooled employment growth rate for 2007-08 and 2008-09 of the same firms.

The left graph shows a close overlap of the employment growth distributions for DNWR 
and non-DNWR firms during the pre-recession period, suggesting that the two groups of firms are indeed very similar prior to the Great Recession, not just in terms of average employment growth but also in terms of the cross-sectional distribution. As the right graph shows, both distributions shift leftwards during the Great Recession but more so for DNWR firms. As we explore more formally below, this indicates that DNWR firms not only destroyed more jobs during the Great Recession than non-DNWR firms but also created less jobs. Finally, as shown in the appendix, the employment growth distributions of DNWR and non-DNWR firms looks again remarkably similar during the recovery period, confirming that DNWR firms on average do not make up for the larger drop in employment growth during the Great Recession.

The results suggest that the excess zero spike indeed captures DNWR constraints that firms can mostly neutralize during normal times - e.g. by compressing wage increases or through more conservative hiring - but that have sizable negative employment effects in times of large unexpected negative shocks such as the Great Recession.

\subsection{Regression results for net employment growth}

We undertake a more systematic analysis of the relation between DNWR and net employment employment growth by estimating a set of firm-level regressions of the form

$$
\begin{aligned}
\triangle y_{j t} & =\alpha+\beta D N W R_{j}+\alpha_{G R} G R+\beta_{G R} D N W R_{j} \times G R \\
& +\alpha_{R E C} R E C+\beta_{R E C} D N W R_{j} \times R E C+\mathbf{X}_{j t}^{\prime} \gamma_{X}+\varepsilon_{j t},
\end{aligned}
$$

where $\triangle y_{j t}$ denotes net employment growth of firm $j$ between the end of year $t-1$ and the end of year $t ; D N W R_{j}$ is an indicator variable taking the value of 1 if firm $j$ has an excess zero spike in 2004-07 and 0 otherwise; $G R$ and $R E C$ are indicator variables taking the value of 1 for the years 2008-2009 and 2010-2012, respectively; $\mathbf{X}_{j t}$ is a vector of firm-specific controls (some of which are time-varying) described below; and $\varepsilon_{j t}$ is an error term. The hypothesis we want to test with equation (2) is whether $\beta_{G R}<0$ and $\beta_{R E C}=0$; i.e. whether DNWR firms experience worse employment growth during the Great Recession and whether this effect persists into the recovery. The identification assumption for these coefficients to have economic meaning is that the pre-recession DNWR indicator is conditionally independent of other factors driving employment growth during the Great Recession and the recovery.

Table 3 reports the results. All regressions are weighted by employment, although results are robust to working with unweighted observations; and standard errors reported in 
parenthesis are clustered at the firm level.

Table 3: Effect of pre-recession excess zero spike on net employment growth

\begin{tabular}{|c|c|c|c|c|c|}
\hline & $(1)$ & $(2)$ & $(3)$ & $(4)$ & $(5)$ \\
\hline Intercept & $\begin{array}{c}2.42 * * * \\
(0.52)\end{array}$ & $\begin{array}{l}0.04 \\
(0.74)\end{array}$ & $\begin{array}{c}6.80 * * * \\
(2.62)\end{array}$ & & \\
\hline Great Recession (year is 2008 or 2009) & $\begin{array}{c}-5.22 * * * \\
(0.52)\end{array}$ & $\begin{array}{c}-1.90 * * * \\
(0.55)\end{array}$ & $\begin{array}{c}-1.38 * * * \\
(0.48)\end{array}$ & $\begin{array}{c}-1.73 * * * \\
(0.25)\end{array}$ & $\begin{array}{c}-11.29 * * * \\
(1.20)\end{array}$ \\
\hline Recovery (year is 2010,2011 , or 2012) & $\begin{array}{c}-1.52 * * * \\
(0.52)\end{array}$ & $\begin{array}{l}-0.63 \\
(0.53)\end{array}$ & $\begin{array}{c}-0.68 \\
(0.56)\end{array}$ & $\begin{array}{c}-2.24 * * * \\
(0.22)\end{array}$ & $\begin{array}{c}-2.37 * * * \\
(0.21)\end{array}$ \\
\hline Excess Zero Spike in 2004-2007 (DNWR indicator) & $\begin{array}{l}-0.28 \\
(0.64)\end{array}$ & $\begin{array}{l}-0.39 \\
(0.75)\end{array}$ & $\begin{array}{l}-0.06 \\
(0.48)\end{array}$ & & \\
\hline Great Recession * Excess Zero Spike & $\begin{array}{c}-2.04 * * * \\
(0.70)\end{array}$ & $\begin{array}{c}-1.48 * * \\
(0.65)\end{array}$ & $\begin{array}{c}-1.34 * * \\
(0.62)\end{array}$ & $\begin{array}{c}-1.25 * * * \\
(0.28)\end{array}$ & $\begin{array}{c}-1.16 * * * \\
(0.28)\end{array}$ \\
\hline Recovery * Excess Zero Spike & $\begin{array}{l}0.02 \\
(0.61) \\
\end{array}$ & $\begin{array}{l}-0.08 \\
(0.59)\end{array}$ & $\begin{array}{l}-0.07 \\
(0.61)\end{array}$ & $\begin{array}{l}-0.16 \\
(0.26)\end{array}$ & $\begin{array}{l}-0.13 \\
(0.26)\end{array}$ \\
\hline Includes industry employment growth & No & Yes & Yes & Yes & Yes \\
\hline Includes firm controls & No & No & Yes & No & No \\
\hline Includes firm fixed effect & No & No & No & Yes & Yes \\
\hline Includes interactions of GR and firm controls & No & No & No & No & Yes \\
\hline
\end{tabular}

Notes: Sample 2004-2012. All regressions are weighted by firm employment. Standard errors in parentheses are clustered at firm level. *** Significant at the $1 \%$ level; ** Significant at the $5 \%$ level; * Significant at the $10 \%$ level

Column (1), which shows estimates from running the regression without any controls, confirms the illustration in Figure 8. The estimate of $\beta$ is negative but small and insignificant, implying that average employment growth for the two types of firms is essentially the same during the pre-recession period. In contrast, the estimate for $\beta_{G R}$ is negative and highly significant, implying that DNWR firms contract employment by about $2 \%$ more annually during the Great Recession than non-DNWR firms. The estimate for $\beta_{R E C}$, in turn, is close to zero and insignificant, which means that this negative effect on employment persists throughout the recovery.

As discussed above, a potential concern is that firms with evidence of DNWR are disproportionally located in industries affected more severely by the Great Recession for reasons other than DNWR. To evaluate this concern, we control for average annual industry employment growth at the NAICS-3 level across Northwestern states (Idaho, Montana, Wyoming, Oregon and Washington), with employment growth of firm $j$ removed. As Column (2) of Table 3 shows, controlling for these industry differences reduces the point estimate of $\beta_{G R}$ to about -1.5 but does not affect the significance of this estimate.

Another potential concern is that the excess zero spike indicator picks up differences in firm efficiency that lead to worse within-industry firm performance during the Great Recession independent of wage rigidity. We therefore add a set of firm-specific variables 
comprised of firm size, average median wage growth, average share of salaried workers, average share of part-time workers, and average share of female workers over the 2004-2007 period. As Column (3) of Table 3 shows, the point estimate of $\beta_{G R}$ with these controls imposed is reduced by only a small amount, which is not surprising given that the excess zero spike indicator is not systematically correlated with any of the firm observables. ${ }^{47}$

To investigate the concern about potential confounds further, we exploit the panel structure of our data and add a firm fixed effect to control for unobservable differences that are reflected in firm-specific employment trends. The pre-recession intercepts $\alpha$ and $\beta$ as well as the firm-specific variables are absorbed by this fixed effect but the other coefficients are still identified and now represent deviations from mean firm employment growth. As Column (4) of Table 3 shows, imposing a firm fixed effect reduces the point estimate $\beta_{G R}$ to -1.25 and at the same time increases the precision of the estimate. Finally, in Column (5), we add the firm-specific variables from above interacted with the GR indicator so as to allow for a differential effect during the Great Recession. This reduces the point estimate for $\beta_{G R}$ to -1.16 without affecting significance. At the same time, the estimate for $\beta_{R E C}$ remains close to zero and insignificant, confirming the above result that the level of employment of DNWR firms remains depressed throughout the recovery relative to non-DNWR firms. We take this as our preferred specification.

The results from these regressions are highly suggestive that DNWR, while far from resulting in complete or almost complete absence of wage cuts, is a relevant constraint with sizable allocative consequences. Indeed, according to our preferred regression specification, DNWR firms contract employment by about $1.15 \%$ more annually during the Great Recession than non-DNWR firms and this effect persists well into the recovery. Abstracting from equilibrium effects that are differenced out, this estimate implies that Washington employment would have declined by about 1\% less if average employment growth of DNWR firms had been the same as the one of non-DNWR firms. ${ }^{48}$ Given that total non-farm employ-

\footnotetext{
${ }^{47}$ In earlier versions of the paper, we also controlled for firm revenue growth and within-industry productivity rank and again found no discernible difference in results. Those regressions necessitated matching the LEHD data to firm-level sales data from the Business Register, which reduced the firm sample further. Since the regression results remain very similar, we decided not to report these results here.

${ }^{48}$ This number is calculated as follows. Take equation (2) and note that $\triangle y_{j t}=100 \times \frac{E_{j t}-E_{j t-1}}{X_{j t}}$ where $X_{j t}=0.5\left(E_{j t}+E_{j t-1}\right)$. The percent difference between actual employment and hypothetical employment of DNWR firms at the end of 2008 if they had had the same employment dynamics as non-DNWR firms (i.e. if $D N W R=0$ ) is then $100 \times \frac{E_{2008}-\tilde{E}_{2008}}{X_{2008}}=\beta_{G R} S_{D N W R}$ where $S_{D N W R}$ is the employment share of DNWR firms. Since $S_{D N W R} \approx 0.5$ and $\beta_{G R}=-1.16$ according to our preferred estimation specification, actual employment in 2008 is $0.58 \%$ lower in 2008 than if employment of DNWR firms had fallen by only as much as non-DNWR firms. Using the same calculation for 2009 then yields the number in the text; i.e. $(1-.0058)^{2}=0.989$ or about $1 \%$ lower.
} 
ment in Washington State declined by $6 \%$ during the Great Recession, this number is quite substantial; even more so if one considers that the extent to which non-DNWR firms were able to cut labor cost through lower non-base pay and reductions in hours worked may also have been quite limited.

\subsection{Regression results for gross employment flows}

Based on these results, it is instructive to examine the relationship between DNWR and different gross employment flow measures. As in Davis et al. (1996) and the ensuing literature, we construct the job creation rate and the job destruction rate for each firm $j$ as $j c_{j t}=\max \left(\triangle y_{j t}, 0\right)$ and $j d_{j t}=\max \left(-\triangle y_{j t}, 0\right)$, respectively. We further exploit the workerfirm matched dimension of the LEHD data to compute the gross hiring rate $h_{j t}$ as the share of new workers hired by firm $j$ during year $t$ and the gross separation rate $s_{j t}$ as the share of workers leaving firm $j$ during year $t$.

As above, all growth rates are defined in percent relative to average firm employment between $t-1$ and $t .{ }^{49}$ By definition, we have $\Delta y_{j t}=j c_{j t}-j d_{j t}=h_{j t}-s_{j t}$, which means that the point estimates for the different components add up to the point estimate for net employment growth.

Table 4: Effect of pre-recession excess zero spike on employment flows

\begin{tabular}{|c|c|c|c|c|c|}
\hline & $\begin{array}{l}\text { Net Employment } \\
\text { Growth Rate } \\
\text { (1) }\end{array}$ & $\begin{array}{l}\text { Job Creation } \\
\text { Rate } \\
\text { (2) }\end{array}$ & $\begin{array}{l}\text { Job Destruction } \\
\text { Rate } \\
\text { (3) }\end{array}$ & $\begin{array}{l}\text { Gross Hiring } \\
\text { Rate } \\
\text { (4) }\end{array}$ & $\begin{array}{c}\text { Gross Separation } \\
\text { Rate } \\
\text { (5) }\end{array}$ \\
\hline Great Recession (year is 2008 or 2009) & $\begin{array}{c}-11.29 * * * \\
(1.20)\end{array}$ & $\begin{array}{c}-5.16 * * * \\
(0.67)\end{array}$ & $\begin{array}{c}6.13 * * * \\
(0.79)\end{array}$ & $\begin{array}{c}-20.79 * * * \\
(1.93)\end{array}$ & $\begin{array}{c}-9.50 * * * \\
(1.89)\end{array}$ \\
\hline Recovery (year is 2010,2011 , or 2012) & $\begin{array}{c}-2.37 * * * \\
(0.21)\end{array}$ & $\begin{array}{c}-1.88 * * * \\
(0.12)\end{array}$ & $\begin{array}{c}0.490 * * * \\
\quad(0.14)\end{array}$ & $\begin{array}{c}-13.64 * * * \\
(0.35)\end{array}$ & $\begin{array}{c}-11.27 * * * \\
(0.34)\end{array}$ \\
\hline Great Recession * Excess Zero Spike & $\begin{array}{c}-1.16 * * * \\
(0.28)\end{array}$ & $\begin{array}{c}-0.29 * \\
(0.16)\end{array}$ & $\begin{array}{c}0.87 * * * \\
(0.19)\end{array}$ & $\begin{array}{c}-2.51 * * * \\
(0.45)\end{array}$ & $\begin{array}{c}-1.35 * * * \\
(0.44)\end{array}$ \\
\hline Recovery * Excess Zero Spike & $\begin{array}{l}-0.13 \\
(0.26)\end{array}$ & $\begin{array}{c}0.36 * * \\
(0.15)\end{array}$ & $\begin{array}{c}0.49 * * * \\
(0.17)\end{array}$ & $\begin{array}{c}-4.87 * * * \\
(0.42)\end{array}$ & $\begin{array}{c}-4.74 * * * \\
(0.41)\end{array}$ \\
\hline $\begin{array}{l}\text { Includes industry employment growth } \\
\text { Includes firm fixed effect } \\
\text { Includes interactions of GR and firm controls }\end{array}$ & $\begin{array}{l}\text { Yes } \\
\text { Yes } \\
\text { Yes }\end{array}$ & $\begin{array}{l}\text { Yes } \\
\text { Yes } \\
\text { Yes }\end{array}$ & $\begin{array}{l}\text { Yes } \\
\text { Yes } \\
\text { Yes }\end{array}$ & $\begin{array}{l}\text { Yes } \\
\text { Yes } \\
\text { Yes }\end{array}$ & $\begin{array}{l}\text { Yes } \\
\text { Yes } \\
\text { Yes }\end{array}$ \\
\hline
\end{tabular}

Notes: Sample 2004-2012. All regressions are weighted by firm employment. Standard errors in parentheses are clustered at firm level.

*** Significant at the $1 \%$ level; ** Significant at the $5 \%$ level; * Significant at the $10 \%$ level

Table 4 reports the estimates. To save on space, we only show estimates for the last regression specification that includes industry growth, firm fixed effects, and firm-specific

\footnotetext{
${ }^{49}$ Notice that because our gross flow rates are calculated at an annual frequency, they are different different from the gross flow rates reported in public-use QWI statistics, which are computed at quarterly frequency.
} 
controls interacted with the GR indicator. For reference, the first column shows the estimates from the net employment growth regression in Column (5) of Table 3. As shown by the second and third column, the effect of the Great Recession on job creation is marginally lower for DNWR firms while the effect on job destruction is significantly higher and about three times as large in absolute value as the effect on job creation, in line with Figure 9. Interestingly, during the recovery, DNWR firms have both higher job creation and job destruction rates than non-DNWR firms, suggesting stronger reorganization among DNWR firms.

As the fourth and fifth column show, DNWR firms exhibit significantly lower gross hiring rates and significantly lower gross separation rates during the Great Recession than nonDNWR firms, with the coefficient estimate for hiring about twice as large as the estimate for separations. The larger decline of employment in DNWR firms during the Great Recessions is therefore driven by less hiring, not more separations - a point to which return below. This suggests that, consistent with models of long-term employment relationships, future constraints on wage setting influence the expected present value of a match and therefore the hiring decision.

Hiring and separations rates of DNWR firms are also estimated to be significantly lower during the recovery period. Interestingly, the coefficient for the hiring rate is estimated to be almost twice as large during the recovery period as during the Great Recession while for the separation rate, this coefficient estimate is 3.5 times as large. As a result, the effects on hiring and separation during the recovery period more or less cancel each other out, explaining the small and insignificant estimate for net employment growth in the first column. At the same time, the estimates suggest that DNWR firms have played an important role for the large and persistent drop in hiring, which accounts for a large part of the anemic labor market performance in the aftermath of the Great Recession (e.g. Elsby et al., 2010), as well as for the decline in the gross reallocation rate (the sum of gross hiring and separation rates) as documented by Davis and Haltiwanger (2014) and many others.

The negative effect of the Great Recession and the recovery period on gross separations may come as a surprise since basic Keynesian theory implies that DNWR-constrained firms should have higher layoff rates and thus a higher separation rate than less constrained firms. It is important to remember, however, that separations in our data include not only layoffs but also quits. In the aggregate, layoffs jump sharply in the beginning of the Great Recession but then drop relatively quickly back to their pre-recession level. Quits, by contrast, decline during the Great Recession and remain lower throughout the recovery because of a persistent decline in job-to-job transitions. Our estimates suggest that this opposing effect on sepa- 
ration from quits is more important for DNWR firms, consistent with a situation in which wages of job stayers in DNWR firms are relatively high from the Great Recession onward and thus dissuade job stayers from engaging in on-the-job search that leads to quits. ${ }^{50}$

\subsection{Additional robustness exercises}

As described above, our baseline estimates control for a host of potential confounds. Here, we perform additional robustness exercises.

Robustness with respect to industry-specific shocks. As shown in Table 3, controlling for industry specific employment growth reduces the estimated effect of the excess zero spike indicator on net employment growth during the Great Recession. We investigate the role of industry differences further by controlling separately for positive and negative industry growth, and by assessing whether employment in DNWR firms reacts to these industry growth shocks differently than employment in non-DNWR firm. To do so, we extend the regression specification in (2) as follows

$$
\begin{aligned}
\triangle y_{j t} & =\alpha+\beta D N W R_{j}+\alpha_{G R} G R+\beta_{G R} D N W R_{j} \times G R \\
& +\alpha_{R E C} R E C+\beta_{R E C} D N W R_{j} \times R E C+\mathbf{X}_{j t}^{\prime} \gamma_{X} \\
& +\mathbf{Z}_{j t}^{\prime} \gamma_{Z}+D N W R_{j} \times \mathbf{Z}_{j t}^{\prime} \beta_{Z}+\varepsilon_{j t} .
\end{aligned}
$$

The first two lines are as in (2). The third line adds a vector of firm industry specific shocks $\mathbf{Z}_{j t}$ as well as the interaction of these industry shocks with the excess zero spike indicator (our measure of DNWR). The industry shocks included in $\mathbf{Z}_{j t}$ are $\triangle \bar{y}_{j t}^{+}=\max \left(0, \triangle \bar{y}_{j t}\right)$ and $\left|\triangle \bar{y}_{j t}^{-}\right|=\max \left(0,-\triangle \bar{y}_{j t}\right)$, where $\triangle \bar{y}_{j t}$ is defined as before as the firm's NAICS-3 industry employment growth level across Northwestern states with employment growth of firm $j$ removed. Furthermore, both of these average industry growth rates are interacted with the GR indicator to allow for a differential effect during the Great Recession; i.e. $\triangle \bar{y}_{j t}^{+} \times G R$ and $\left|\triangle \bar{y}_{j t}^{-}\right| \times G R$.

Table 5 shows the results. For comparison, Column (1) repeats the estimates from the baseline regression without any controls or firm fixed effects; i.e. column (1) in Table 5. Column (2) shows the results of adding the different industry shocks in $\mathbf{Z}_{i t}$ and their interaction with the excess zero spike indicator, again without any firm controls or firm fixed effect.

\footnotetext{
${ }^{50}$ Of course, it would be interesting to investigate the effect of DNWR on layoffs and quits separately. As Haltiwanger et al. (2015) show, distinguishing between these two parts of separation in the LEHD is possible under certain assumptions. However, for our sample, this would entail substantial additional data work. We therefore leave this point unexplored for now.
} 
Similar to the baseline regression in Column (2) of Table 5, adding industry shocks leads to a reduction in the estimate of $\beta_{G R}$ but remains highly significant. This confirms that DNWR firms are disproportionally located in industries affected more severely by the Great Recession. The coefficient estimates on the different industry shocks $\mathbf{Z}_{j t}$ have the expected sign: firms located in expanding industries have higher employment growth than firms located in contracting industries. ${ }^{51}$ Interestingly, DNWR firms are not significantly more sensitive to negative industry growth shocks than non-DNWR firms, presumably because most of these negative shocks occur during the Great Recession and are therefore covered by the GR indicator.

Table 5: Regression results with industry shocks

Dependent variable: annual log change in firm employment

\begin{tabular}{|c|c|c|c|c|c|}
\hline & $(1)$ & $(2)$ & (3) & $(4)$ & $(5)$ \\
\hline Intercept & $\begin{array}{c}2.42 * * * \\
(0.52)\end{array}$ & $\begin{array}{l}1.21 \\
(0.86)\end{array}$ & $\begin{array}{c}7.55^{* * * *} \\
(2.55)\end{array}$ & & \\
\hline Great Recession (year is 2008 or 2009) & $\begin{array}{c}-5.22 * * * \\
(0.52)\end{array}$ & $\begin{array}{c}-1.50 * * * \\
(0.56)\end{array}$ & $\begin{array}{c}-1.06 * * \\
(0.54)\end{array}$ & $\begin{array}{c}-1.51 * * * \\
(0.28)\end{array}$ & $\begin{array}{c}-10.82 * * * \\
(1.22)\end{array}$ \\
\hline Recovery (year is 2010,2011 , or 2012) & $\begin{array}{c}-1.52 * * * \\
(0.52)\end{array}$ & $\begin{array}{c}-1.053 * * \\
(0.58)\end{array}$ & $\begin{array}{l}-0.91 \\
(0.57)\end{array}$ & $\begin{array}{c}-2.27 * * * \\
(0.22)\end{array}$ & $\begin{array}{c}-2.40 * * * \\
(0.22)\end{array}$ \\
\hline Excess Zero Spike in 2004-2007 (DNWR indicator) & $\begin{array}{l}-0.28 \\
(0.64)\end{array}$ & $\begin{array}{l}-0.33 \\
(0.71)\end{array}$ & $\begin{array}{l}-0.05 \\
(0.48)\end{array}$ & & \\
\hline Great Recession * Excess Zero Spike & $\begin{array}{c}-2.04 * * * \\
(0.70)\end{array}$ & $\begin{array}{c}-1.617 * * \\
(0.72)\end{array}$ & $\begin{array}{c}-1.46^{*} \\
(0.70)\end{array}$ & $\begin{array}{c}-1.18 * * * \\
(0.33)\end{array}$ & $\begin{array}{c}-1.13 * * * \\
\quad(0.33)\end{array}$ \\
\hline Recovery * Excess Zero Spike & $\begin{array}{c}0.02 \\
(0.61)\end{array}$ & $\begin{array}{l}-0.03 \\
(0.60)\end{array}$ & $\begin{array}{l}-0.05 \\
(0.62)\end{array}$ & $\begin{array}{l}-0.17 \\
(0.26)\end{array}$ & $\begin{array}{l}-0.14 \\
(0.26)\end{array}$ \\
\hline Industry employment growth rate $(>0)$ & & $\begin{array}{c}0.29 * * * \\
\quad(0.10)\end{array}$ & $\begin{array}{c}0.50 * * * \\
(0.06)\end{array}$ & $\begin{array}{c}0.76 * * * \\
(0.03)\end{array}$ & $\begin{array}{c}0.70 * * * \\
(0.03)\end{array}$ \\
\hline Industry employment growth rate $(<0)$ & & $\begin{array}{c}-0.57^{*} \\
(0.33)\end{array}$ & $\begin{array}{l}-0.32 \\
(0.32)\end{array}$ & $\begin{array}{c}-0.39 * * \\
(0.19)\end{array}$ & $\begin{array}{c}-0.38^{*} \\
(0.19)\end{array}$ \\
\hline Industry empl. growth rate $(<0) *$ Excess zero spike & & $\begin{array}{l}-0.03 \\
(0.36)\end{array}$ & $\begin{array}{l}-0.18 \\
(0.35)\end{array}$ & $\begin{array}{l}0.15 \\
(0.21)\end{array}$ & $\begin{array}{c}0.09 \\
(0.21)\end{array}$ \\
\hline Industry empl. growth rate $(<0) * \mathrm{GR}$ & & $\begin{array}{l}-0.42 \\
(0.32)\end{array}$ & $\begin{array}{c}-0.61 * * \\
(0.31)\end{array}$ & $\begin{array}{c}-0.48 * * \\
(0.19)\end{array}$ & $\begin{array}{c}-0.45 * * \\
(0.19)\end{array}$ \\
\hline Industry empl. growth rate $(<0) *$ Excess Zero Spike * GR & & $\begin{array}{c}0.12 \\
(0.38)\end{array}$ & $\begin{array}{c}0.24 \\
(0.36)\end{array}$ & $\begin{array}{l}-0.15 \\
(0.22)\end{array}$ & $\begin{array}{l}-0.08 \\
(0.22)\end{array}$ \\
\hline Includes firm controls & No & No & Yes & No & No \\
\hline Includes firm fixed effects & No & No & No & Yes & Yes \\
\hline Includes interactions of GR and firm controls & No & No & No & No & Yes \\
\hline
\end{tabular}

Notes: Sample 2004-2012. All regressions are weighted by firm employment. Standard errors in parentheses are clustered at firm level. *** Significant at the $1 \%$ level; ** Significant at the $5 \%$ level; * Significant at the $10 \%$ level

As Columns (3) to (5) show, very similar results obtain when firm-specific controls and firm fixed effects are added. In particular, the coefficient estimate for $\beta_{G R}$ is reduced further

\footnotetext{
${ }^{51}$ To save on space, the regressions abstract from the interaction terms of positive industry growth with the GR indicator since these effects are estimated to be small and insignificant.
} 
to about -1.15 but remains highly significant, as in the regressions in Table 3.

Robustness with respect to alternative measures of DNWR. Table 6 reports estimation results for the regression on net employment growth in (2) but using our alternative asymmetry statistics as measures of DNWR; i.e the proportion of zero wage changes, excess zero spike, and missing mass left of zero. All of these statistics are computed at the firm level for the pre-recession period 2004-2007, and all estimates shown include the different controls and the firm fixed effect. For comparison, the first column displays the coefficient estimates for the regression in column (5) of Table 5. Columns (2) - (5) largely confirm these results: all of the alternative DNWR measures are estimated to exert a highly significant negative effect on firm employment growth during the Great Recession but a much smaller and generally insignificant effect during the recovery.

Table 6: Regression results for alternative DNWR measures

Dependent variable: annual log change in firm employment

\begin{tabular}{|c|c|c|c|c|}
\hline & \multicolumn{4}{|c|}{ DNWR measure } \\
\hline & $\begin{array}{c}\text { Excess Zero } \\
\text { Spike Indicator } \\
\text { (1) }\end{array}$ & $\begin{array}{c}\text { Proportion of } \\
\text { Zeros } \\
\text { (2) }\end{array}$ & $\begin{array}{c}\text { Excess Zero } \\
\text { Spike } \\
\text { (3) }\end{array}$ & $\begin{array}{c}\text { Missing Mass } \\
\text { of Wage Cuts } \\
\text { (4) }\end{array}$ \\
\hline Great Recession (year is 2008 or 2009) & $\begin{array}{c}-11.29 * * * \\
(1.20)\end{array}$ & $\begin{array}{c}-11.53^{* * *} \\
(1.19)\end{array}$ & $\begin{array}{c}-11.65^{* * *} \\
(1.19)\end{array}$ & $\begin{array}{c}-9.40 * * * \\
(1.21)\end{array}$ \\
\hline Recovery (year is 2010,2011 , or 2012) & $\begin{array}{c}-2.37 * * * \\
(0.21)\end{array}$ & $\begin{array}{c}-2.70 * * * \\
(0.18)\end{array}$ & $\begin{array}{c}-2.48 * * * \\
(0.14)\end{array}$ & $\begin{array}{c}-1.94 * * * \\
(0.19)\end{array}$ \\
\hline Great Recession * DNWR & $\begin{array}{c}-1.16^{* * *} \\
(0.28)\end{array}$ & $\begin{array}{c}-1.24 * * * \\
(0.03)\end{array}$ & $\begin{array}{c}-0.24 * * * \\
(0.04)\end{array}$ & $\begin{array}{c}-0.21 * * * \\
(0.02)\end{array}$ \\
\hline Recovery * DNWR & $\begin{array}{l}-0.13 \\
(0.26)\end{array}$ & $\begin{array}{c}0.05 * * \\
(0.03)\end{array}$ & $\begin{array}{l}0.01 \\
(0.03)\end{array}$ & $\begin{array}{c}-0.07 * * * \\
(0.02)\end{array}$ \\
\hline Includes industry employment growth & Yes & Yes & Yes & Yes \\
\hline Includes firm fixed effect & Yes & Yes & Yes & Yes \\
\hline Includes interactions of GR and firm controls & Yes & Yes & Yes & Yes \\
\hline
\end{tabular}

Notes: Sample 2004-2012. All regressions are weighted by firm employment. Standard errors in parentheses are clustered at firm level. *** Significant at the $1 \%$ level; ** Significant at the $5 \%$ level; * Significant at the $10 \%$ level

In sum, the two robustness checks confirm the baseline results from before: firms with indicators of DNWR in the pre-recession period are estimated to have systematically more negative employment outcomes during the Great Recession, and this effect lasts well into the recovery. The fact that this message is consistent across all different measures of DNWR provides further confirmation that these regressions indeed pick up negative allocative effects of wage setting constraints. 


\section{Conclusion}

In this paper, we use worker-firm linked administrative data from the LEHD program for a large, nationally representative U.S. state to make several new contributions to the literature on DNWR. First, we show that prior to the Great Recession, only about 7-8\% of job stayers are paid the same nominal hourly wage as one year earlier - substantially less than previously found in survey-based data - and wage cuts are far from a rare occurrence. We also find that during the Great Recession, the incidence of wage cuts increases, followed by an important rise in the proportion of zero wage changes as the economy starts to recover. Second, we show that earnings are even more flexible than hourly wage rates, due to systematic variations in hours. In particular, reductions in hours account for a substantially larger part of earnings declines than wage cuts, which is suggestive of DNWR playing an allocative role at the intensive (hours) margin. Third, we show that firms with pre-recession indicators of DNWR exhibit significantly lower employment growth during the Great Recession. This effect is primarily driven by lower hiring rates and persists well into the recovery. These results are robust to a firm fixed effects, various controls, and different ways of measuring DNWR. Furthermore, we show that the pre-recession employment growth distribution of firms with indicators of DNWR looks essentially identical to the one of firms without indicators of DNWR. This makes it unlikely that the negative employment effects of DNWR during the Great Recession are driven by confounding factors.

Our results contradict the hypothesis of a strongly binding DNWR constraint that figures prominently in many policy discussions and is also a key ingredient in a number of recent prominent business cycle models. Our results also represent a challenge for New Keynesian models of infrequent wage contracting. None of this implies that wage setting is not subject to rigidities that have allocative consequences. Indeed, our results together with ongoing work by Grigsby et al. (2018) indicate that while wages adjusts frequently both upward and downward once all forms of compensation and hours variations are taken into account, the extent of downward flexibility in wages is limited by the fact that base pay is almost never cut and that non-base pay accounts on average for only a small part of total compensation. In other words, DNWR may still be a relevant constraint. We argue that the apparent limited downward flexibility of wages can explain the increased incidence of wage cuts during the Great Recession followed by the increase in wage freezes as the economy starts to recover; and why our regression estimates show that DNWR has sizable negative employment effects in response to an unexpected large negative shock such as the Great Recession. 


\section{References}

Abbritti, M. and S. Fahr (2013). Downward wage rigiditiies and business cycle asymmetries. Journal of Monetary Economics 60, 871-886. 33

Abowd, J. M., B. E. Stephens, L. Vilhuber, K. L. McKinney, M. Roemer, and S. Woodcock (2009). Producer Dynamics: New Evidence from Micro Data, Chapter The LEHD Infrastructure Files and the Creation of the Quarterly Workforce Indicators, pp. 149-230. National Bureau of Economic Research. 16

Aghion, P., N. Bloom, B. Lucking, R. Sadun, and J. V. Reenen (2017). Turbulence, firm decentralization and growth in bad times. Technical Report 23354, NBER Working Paper. 8

Akerlof, G. A., W. T. Dickens, and G. L. Perry (1996). The macroeconomics of low inflation. Brookings Papers on Economic Activity 1, 1-59. 3, 3.1

Alfaro, L. and M. Chen (2012). Surviving the global financial crisis: Foreign ownership and establishment performance. American Economic Journal: Economic Policy 4(3), 30-55. 8

Altonji, J. G. and P. J. Devereux (2000). The extent and consequences of downward nominal wage rigidity. Worker Well-Being 19(383-431). 3, 3.1, 36

Auclert, A. and M. Rognlie (2016). Inequality and aggregate demand. 31

Babecky, J., P. D. Caju, T. Kosma, J. Messina, and T. Room (2012). How do european firms adjust their labour costs when nominal wages are rigid? Labour Economics 19, 792-801. 36

Barratieri, A., S. Basu, and P. Gottschalk (2014). Some evidence on the importance of sticky wages. American Economic Journal: Macroeconomics 6, 70-101. 3, 3.1

Barro, R. J. (1977). Long-term contracting, sticky prices, and monetary policy. Journal of Monetary Economics 3(3), 305-316. 2

Basu, S. and C. L. House (2016). Allocative and Remitted Wages: New Facts and Challenges for Keynesian Models, Volume 2A of Handbook of Macroeconomics, Chapter 6, pp. 297354. Elsevier. 2

Becker, G. S. (1962). Investment in human capital: a theoretical analysis. Journal of Political Economy 70(5), 9-49. 1

Benigno, P. and L. A. Ricci (2011). The inflation-output trade-off with downward wage rigidities. American Economic Review 101, 1436-1466. 33

Bewley, T. F. (1999). Why Wages Don't Fall during a Recession. Harvard University Press. 23,44 
Bihan, H. L., J. Montornès, and T. Heckel (2012). Sticky wages: Evidence from quartelry microeconomic data. American Economic Journal: Macroeconomics 4(3), 1-32. 1

Borowczyk-Martins, D. and E. Lalé (2018). Employment adjustment and part-time work: Lessons from the united states and the united kingdom. American Economic Journal: Macroeconomics (forthcoming). 1, 43, 3.3

Bound, J., C. Brown, G. J. Duncan, and W. L. Rodgers (1991). Measurement error in crosssectional and longitudinal labor market surveys: Results from two validation studies. Journal of Labor Economics 9(1), 1-24. 4

Card, D. and D. Hyslop (1997). Does inflation'grease the wheels of the labor market? In C. D. Romer and D. H. Romer (Eds.), Reducing Inflation: Motivation and Strategy. University of Chicago Press. 3, 3

Carneiro, A., P. Portugal, and J. Varejão (2014). Catastrophic job destruction during the portuguese economic crisis. Journal of Macroeconomics 39(B), 444-457. 1

Castellano, S. G., R. García-Verdú, and D. S. Kaplan (2004). Nominal wage rigidities in mexico: evidence from social security records. Journal of Development Economics 75, 507-533. 1

Chodorow-Reich, G. (2014). The employment effects of credit market disruptions: Firm-level evidence from the 2008-9 financial crisis. Quarterly Journal of Economics 129(1), 1-59. 8

Christiano, L. J., M. Eichenbaum, and C. L. Evans (2005). Nominal rigidities and the dynamic effects of a shock to monetary policy. Journal of Political Economy 113(1), $1-45.1,32$

CNBC (2016, September). Boeing to curb overtime for us salaried workers to reduce costs. 24

Daly, M. and B. Hobijn (2014). Downward nominal wage rigidities bend the phillips curve. Journal of Money, Credit, and Banking 46(2), 51-93. 3, 1, 3.1, 33, 34

Davis, S. J. and J. Haltiwanger (2014). Labor market fluidity and economic performance. Working paper, National Bureau of Economic Research. 4.3

Davis, S. J., J. C. Haltiwanger, and S. Schuh (1996). Job Creation and Destruction. MIT Press. 4.3

Dickens, W. T., L. Goette, E. L. Groshen, S. Holden, J. Messina, M. E. Schweitzer, J. Turunen, and M. Ward (2007). How wages change: Micro evidence from the international wage flexbility project. Journal of Economic Perspectives 21(2), 195-214. 3, 34

Dupraz, S., E. Nakamura, and J. Steinsson (2016). A plucking model of business cycles. 31 Economist (2014, September 6). Wage stagnation: The big freeze. 1 
Eggertsson, G. B. and N. R. Mehrotra (2015). A model of secular stagnation. 31

Ehrlich, G. and J. Montes (2018). Wage rigidity and employment outcomes: Evidence from administrative data. 1

Elsby, M. W. L. (2009). Evaluating the economic significance of downward nominal wage rigidity. Journal of Monetary Economics 56, 154-169. 3, 1, 11, 3, 4, 46

Elsby, M. W. L., B. Hobijn, and A. Sahin (2010). The labor market in the great recession. Brookings Papers on Economic Activity 1, 1-48. 4.3

Elsby, M. W. L., D. Shin, and G. Solon (2016). Wage adjustment in the great recession and other downturns: Evidence from the united states and great britain. Journal of Labor Economics 34(1), S249-S291. 3, 1, 3.1, 34

Elsby, M. W. L. and G. Solon (2018). How prevalent is downward rigidity in nominal wages? evidence from payroll records and pay slips. Working Paper 25393, National Bureau of Economic Research. 15

Fallick, B., M. Lettau, and W. Wascher (2016). Downward nominal wage rigidity in the united states during and after the great recession. Working paper 16-02, Federal Reserve Bank of Cleveland. 3, 35

Fehr, E. and S. Gächter (2000). Fairness and retaliation: The economics of reciprocity. Journal of Economic Perspectives 14(3), 159-181. 23

Giroud, X. and H. M. Mueller (2017). Firm leverage, consumer demand, and employment losses during the great recession. Quarterly Journal of Economics 132(1), 271-316. 8

Gottschalk, P. (2005). Downward nominal wage flexibility: Real or measurement error? Review of Economics and Statistics 87(3), 556-568. 3, 34, 3.1

Grigsby, J., E. Hurst, and A. Yildirmaz (2018). Aggregate nominal wage adjustments: New evidence from administrative payroll data. 1, 14, 20, 3.1, 38, 5

Guvenen, F., S. Ozkan, and J. Song (2014). The nature of countercylical income risk. Journal of Political Economy 122(3), 621-660. 1, 3, 3.3

Haltiwanger, J., H. Hyatt, and E. McEntarfer (2015). Cyclical reallocation of workers across employers by firm size and wage. Working paper 21235, NBER. 50

Heckman, J. J. (1993). What has been learned about labor supply in the past twenty years? American Economic Review 83(2), 116-121. 4

Jardim, E., M. C. Long, R. Plotnick, E. van Inwegen, J. L. Vigdor, and H. Wething (2017). Minimum wage increases, wages, and low-wage employment: Evidence from seattle. Technical Report Working Paper No. 23532, National Bureau of Economic Research. 13

Jardim, E., G. Solon, and J. Vigdor (2018). How prevalent is downward rigidity in nominal 
wages? evidence from payroll records in washington state. 1

Kahn, S. (1997). Evidence of nominal wage stickiness from microdata. American Economic Review 87(5), 993-1008. 3, 3, 34

Keynes, J. M. (1936). The General Theory of Employment, Interest, and Money. 1

Kim, J. and F. Ruge-Murcia (2009). How much inflation is necessary to grease the wheels? Journal of Monetary Economics 56, 365-377. 31

Krugman, P. (2012, July 22). Sticky wages and the macro story. 1

Kurmann, A., E. McEntarfer, and J. R. Spletzer (2016). Downward wage rigidity in the united states: New evidence from administrative data. 1, 2.4

Lachowska, M., A. Mas, and S. A. Woodbury (2017). Sources of displaced workers' long-term earnings losses. 13

Lachowska, M., A. Mas, and S. A. Woodbury (2018). How reliable are administrative reports of paid work hours? 13, 2.3

Lazaer, E. P. and K. L. Shaw (2007). Personnel economics: The economist's view of human resources. Journal of Economic Perspectives 21(4), 91-114. 23

Lebow, D. E., R. E. Saks, and B. A. Wilson (2003). Downward nominal wage rigidity: Evidence from the employment cost index. Advances in Macroeconomics 3(1). 3, 3

McLaughlin, K. (1994). Rigid wages? Journal of Monetary Economics 34, 383-414. 3

Nickell, S. and G. Quintini (2003). Nominal wage rigidity and the rate of inflation. Economic Journal 113(490), 762-781. 1

Park, S. and D. Shin (2017). The extent and nature of downward nominal wage flexibility: An analysis of the longitudinal worker/establishment data from korea. Labour Economics 48, 67-86. 1

Pissarides, C. A. (2009). The unemployment volatility puzzle: Is wage stickiness the answer? Econometrica 77(5), 1339-1369. 2

Schmitt-Grohe, S. and M. Uribe (2013). Downward nominal wage rigidity and the case for temporary inflation in the eurozone. Journal of Economic Perspectives 27(3), 193-212. 31

Schmitt-Grohe, S. and M. Uribe (2016). Downward nominal wage rigidity, currency pegs, and involuntary unemployment. Journal of Political Economy 124(5), 1466-1514. 31

Schmitt-Grohe, S. and M. Uribe (2017). Liquidity traps and jobless recoveries. American Economic Journal: Macroeconomics 9(1), 165-204. 31

Shin, D. and G. Solon (2007). New evidence on real wage cyclicality within employeremployee matches. Scottish Journal of Political Economy 54(5), 648-660. 3.1 
Siggurdsson, J. and R. Sigurdardottir (2016). Time-dependent or state-dependent wagesetting? evidence from periods of macroeconomic instability. Journal of Monetary Economics 78, 50-66. 1

Smets, F. and R. Wouters (2007). Shocks and frictions in US business cycles: A bayesian DSGE approach. American Economic Review 97(3), 586-606. 1, 32

Smith, J. C. (2000). Nominal wage rigidity in the united kingdom. Economic Journal 110, C176-C195. 35

Tobin, J. (1972). Inflation and unemployment. American Economic Review 61(1/2), 1-18. 1

Vilhuber, L. and K. L. McKinney (2014). Lehd infrastructure files in the census rdc overview. Technical Report 14-26, Center for Economic Studies, U.S. Census Bureau. 16 Yellen, J. L. (2016, October 14). Macroeconomic research after the crisis. 1 


\section{A Appendix (For Online Publication)}

\section{A.1 Additional Figures and Tables}

Table A.1: Characteristics of distributional statistics, 2004-2007 (continued)

Dependent variables: various measures of Downward Nominal Wage Rigidity at the firm level, 2004-2007

\begin{tabular}{|c|c|c|c|c|}
\hline & $\begin{array}{c}\text { Mass of Zero } \\
\text { Wage Changes } \\
\text { (1) }\end{array}$ & $\begin{array}{c}\text { Excess Zero } \\
\text { Spike } \\
(2)\end{array}$ & $\begin{array}{c}\text { Excess Zero } \\
\text { Spike Indicator } \\
\text { (3) }\end{array}$ & $\begin{array}{c}\text { Missing Mass } \\
\text { of Wage Cuts } \\
\text { (4) }\end{array}$ \\
\hline \multirow[t]{2}{*}{ Mining \& Utilities } & -0.90 & -0.74 & 0.07 & $-3.09 * *$ \\
\hline & $(0.64)$ & $(0.50)$ & $(0.14)$ & (1.59) \\
\hline \multirow[t]{2}{*}{ Construction } & $1.40 * * *$ & $0.98 * * *$ & $0.12 *$ & $1.81 * *$ \\
\hline & $(0.44)$ & $(0.31)$ & $(0.07)$ & $(0.80)$ \\
\hline \multirow[t]{2}{*}{ Manufacturing } & 0.28 & -0.14 & 0.07 & 0.15 \\
\hline & $(0.40)$ & $(0.24)$ & $(0.08)$ & $(0.86)$ \\
\hline \multirow[t]{2}{*}{ Wholesale Trade } & $1.09 * * *$ & $0.71 * *$ & $0.13 * *$ & 0.56 \\
\hline & $(0.40)$ & $(0.28)$ & $(0.06)$ & $(0.76)$ \\
\hline \multirow[t]{2}{*}{ Retail Trade } & $1.01 * *$ & $0.63 * *$ & 0.04 & -0.19 \\
\hline & $(0.42)$ & $(0.32)$ & $(0.09)$ & (1.07) \\
\hline \multirow[t]{2}{*}{ Transportation \& Warehousing } & 0.92 & -0.09 & 0.01 & 0.88 \\
\hline & $(0.74)$ & $(0.36)$ & $(0.11)$ & $(1.28)$ \\
\hline \multirow[t]{2}{*}{ Information } & 0.55 & -0.42 & -0.23 & $-3.30 * *$ \\
\hline & $(0.43)$ & $(0.33)$ & $(0.17)$ & $(1.50)$ \\
\hline \multirow[t]{2}{*}{ Finance and Insurance } & $-0.93 * * *$ & $-0.71 * * *$ & $0.12 *$ & $-2.31 * *$ \\
\hline & $(0.35)$ & $(0.25)$ & $(0.08)$ & $(1.11)$ \\
\hline \multirow[t]{2}{*}{ Real Estate } & $2.03 * * *$ & $1.35 * *$ & $0.15 *$ & $2.31 * *$ \\
\hline & $(0.71)$ & $(0.54)$ & $(0.08)$ & $(1.18)$ \\
\hline \multirow[t]{2}{*}{ Admin Support \& Waste Management } & $3.10 * * *$ & $2.51 * * *$ & 0.11 & $1.94 *$ \\
\hline & $(0.74)$ & $(0.70)$ & $(0.09)$ & (1.13) \\
\hline \multirow[t]{2}{*}{ Education } & 0.60 & 0.02 & -0.03 & $2.38 * *$ \\
\hline & $(0.89)$ & $(0.63)$ & $(0.10)$ & (1.17) \\
\hline \multirow[t]{2}{*}{ Health Care } & 0.43 & -0.16 & 0.04 & -0.43 \\
\hline & $(0.40)$ & $(0.29)$ & $(0.08)$ & $(0.89)$ \\
\hline \multirow[t]{2}{*}{ Arts and Entertainment } & $3.40 * * *$ & $2.67 * * *$ & $0.17 * * *$ & $3.40 * * *$ \\
\hline & $(0.70)$ & $(0.57)$ & $(0.10)$ & (1.18) \\
\hline \multirow[t]{2}{*}{ Accomodation and Food Service } & $1.36^{* * *}$ & $0.93 * * *$ & $0.26^{* * *}$ & $2.95 * * *$ \\
\hline & $(0.45)$ & $(0.35)$ & $(0.08)$ & $(0.98)$ \\
\hline
\end{tabular}

Notes: Sample 2004-2007 of firms with at least 50 job stayers. Omitted industry category is Professional Services. All regressions are weighted by firm employment. Standard errors in parentheses are clustered at firm level.

*** Significant at the $1 \%$ level; ** Significant at the $5 \%$ level; * Significant at the $10 \%$ level 
Table A.2: Hours change regressions. Washington State, 1998-2013

Dependent variable: annual log hours change

\begin{tabular}{|c|c|c|c|c|c|}
\hline & $\begin{array}{l}\text { All job- } \\
\text { stayers } \\
(1)\end{array}$ & $\begin{array}{l}\text { All job- } \\
\text { stayers } \\
(2)\end{array}$ & $\begin{array}{c}\text { All job- } \\
\text { stayers } \\
(3)\end{array}$ & $\begin{array}{l}\text { All job- } \\
\text { stayers } \\
(4)\end{array}$ & $\begin{array}{c}\text { Full-time job- } \\
\text { stayers } \\
(5)\end{array}$ \\
\hline Annual log earnings change & $\begin{array}{c}0.55 * * \\
(0.00)\end{array}$ & & & & \\
\hline Annual log earnings change $(<0)$ & & $\begin{array}{c}0.72 * * \\
(0.00)\end{array}$ & $\begin{array}{c}0.72 * * \\
(0.00)\end{array}$ & $\begin{array}{c}0.73 * * \\
(0.00)\end{array}$ & \\
\hline Annual log earnings change $(\geq 0)$ & & $\begin{array}{c}0.44 * * \\
(0.00)\end{array}$ & $\begin{array}{c}0.45 * * \\
(0.00)\end{array}$ & $\begin{array}{c}0.45 * * \\
(0.00)\end{array}$ & \\
\hline Annual log earnings change $(<0)$ & & & & & $\begin{array}{c}0.64 * * \\
(0.00)\end{array}$ \\
\hline Annual log earnings change $(\geq 0)$ & & & & & $\begin{array}{c}0.28 * * \\
(0.00)\end{array}$ \\
\hline Includes demographic controls & No & No & Yes & No & Yes \\
\hline Includes firm controls & No & No & Yes & No & Yes \\
\hline Includes firm fixed effects & No & No & No & Yes & No \\
\hline
\end{tabular}

Notes: Sample 1998-2013. Standard errors in parentheses are clustered at the job stayer level.

*** Significant at the $1 \%$ level; ** Significant at the $5 \%$ level; * Significant at the $10 \%$ level 
Figure A.1: Distribution of hours levels and hours changes, selected years.

(a) Distribution of weekly hours paid in 2006, two-year job stayers

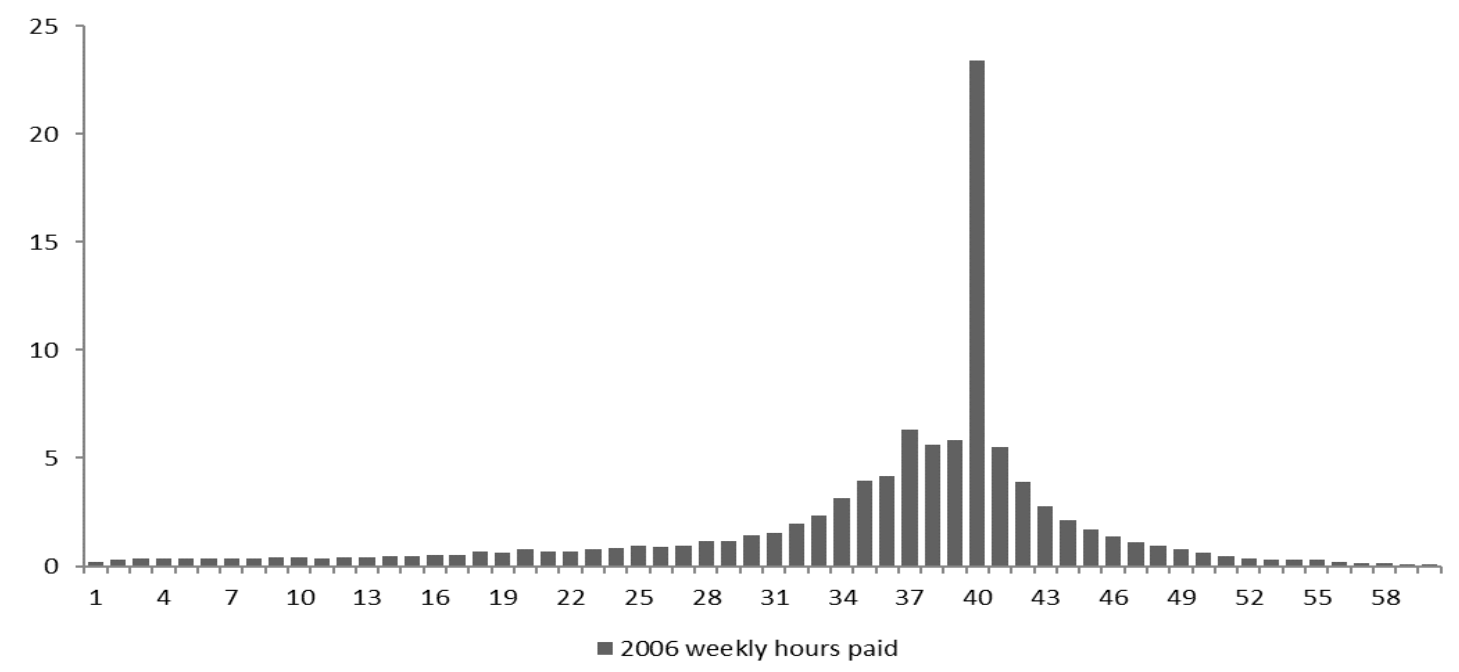

(b) Distribution of change in weekly hours paid in 2009 , by hours paid in 2008 , two-year job stayers

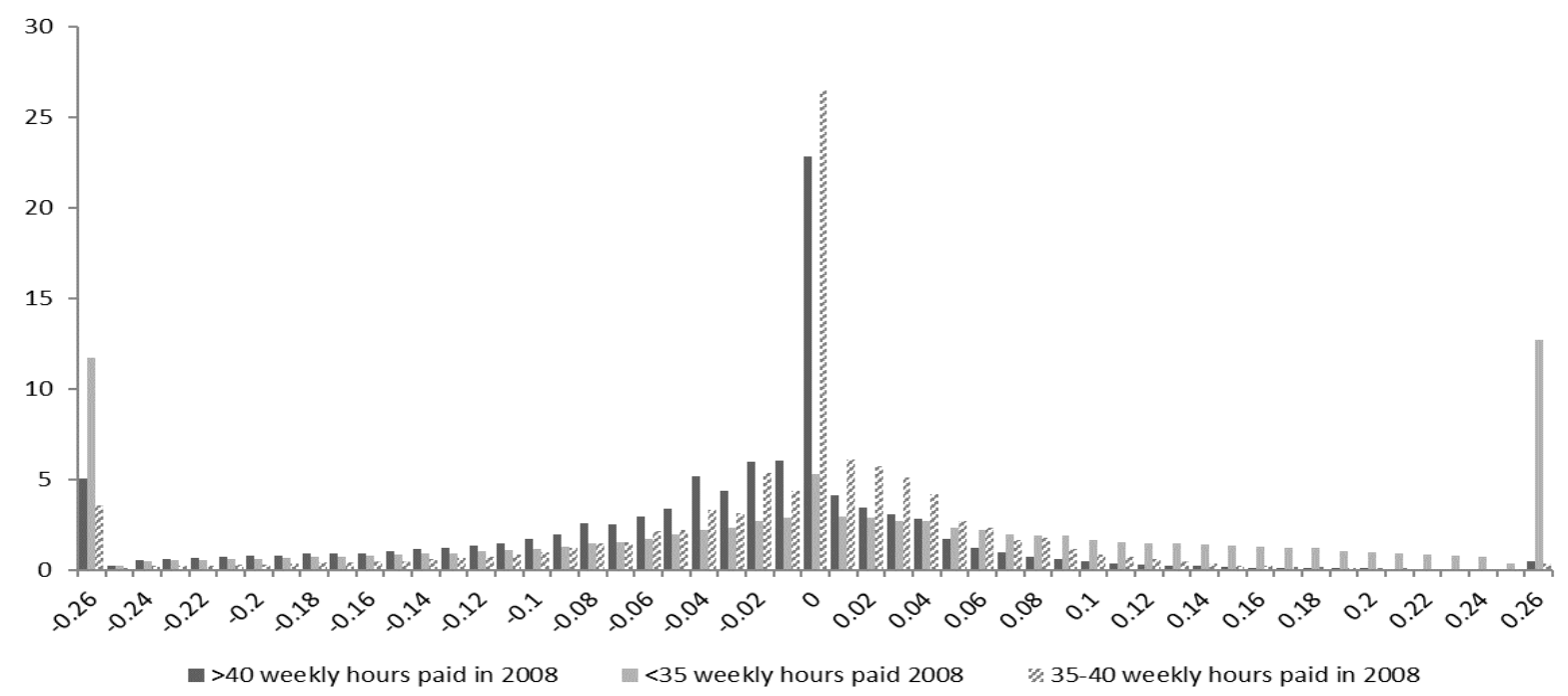

Notes: Washington state job stayer sample. Panel (a) shows distribution of average weekly hours in 2006. Panel (b) shows distribution of year-to-year log hours changes for 2008-2009 by average weekly hours in 2008. The first and last bar of each histogram in Panel (b) contain all observations smaller than -0.255 and observations exceeding 0.255 , respectively. 
Figure A.2: Washington State and U.S. Employment, 1998:3-2014:1

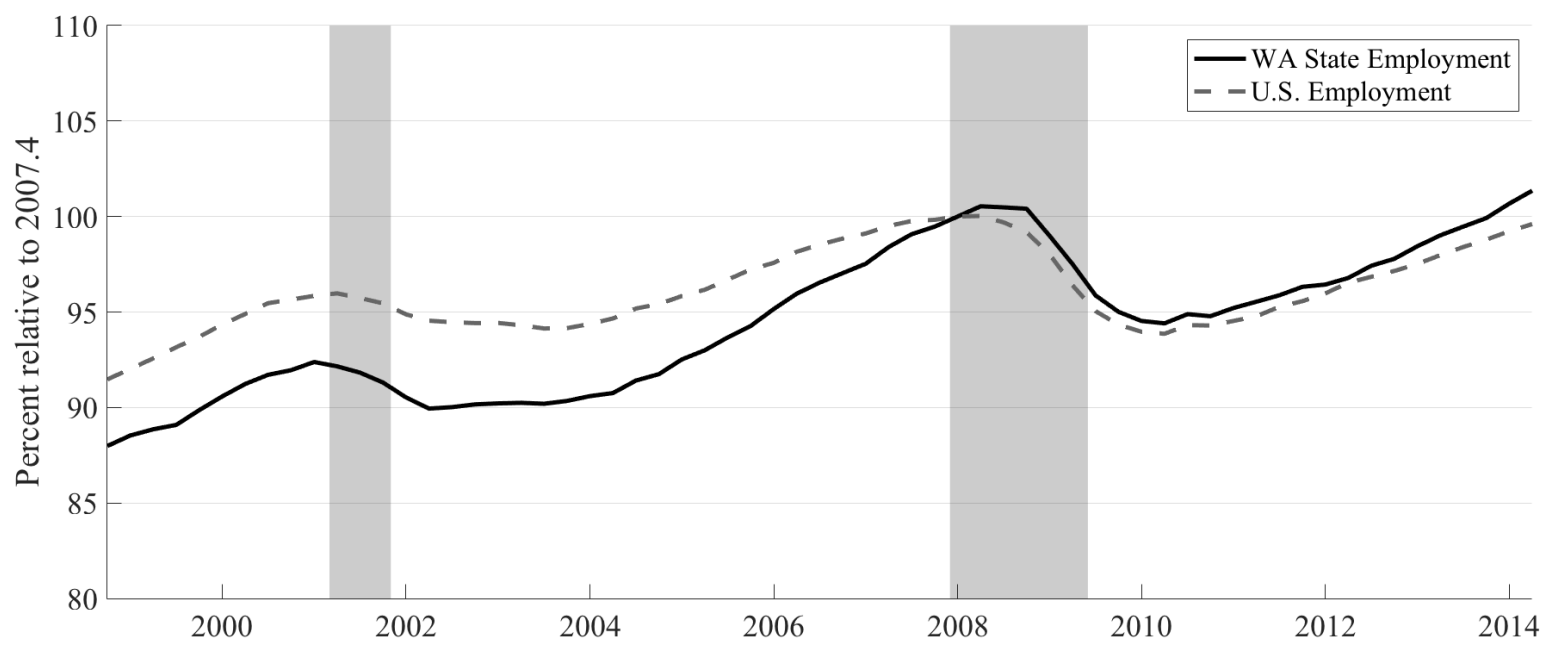

Notes: Total Nonfarm Employment in Washington and the U.S.; quarterly, seasonally adjusted, normalized to 100 in 2007:4. Source: U.S. Bureau of Labor Statistics, retrieved from FRED, Federal Reserve Bank of St. Louis; https://fred.stlouisfed.org/series/WANA and https://fred.stlouisfed.org/series/PAYEMS. Grey bars shows NBER recession dates. 
Figure A.3: Distribution of hourly wage changes of job stayers, 1998:3-2014:1

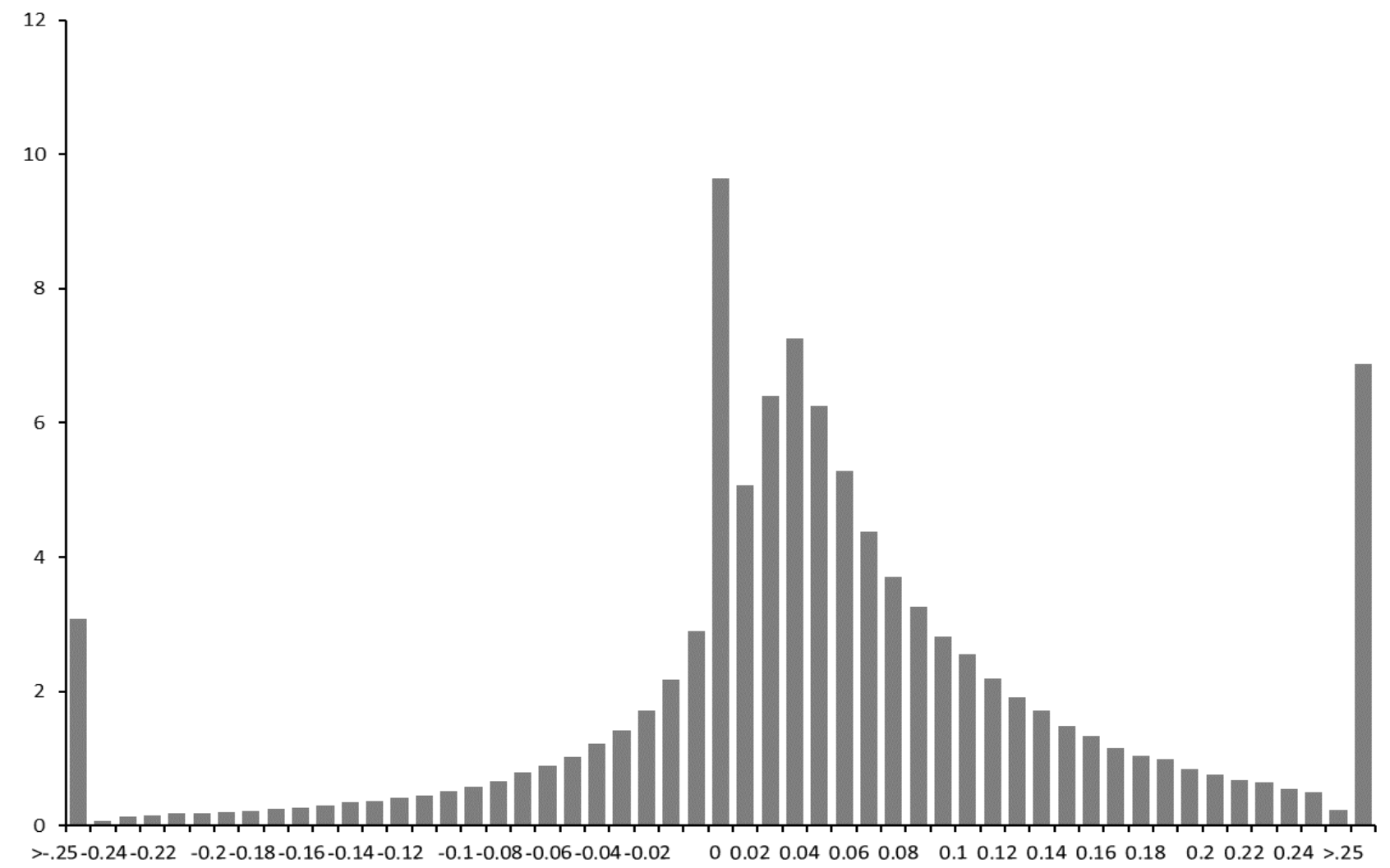

Notes: Washington state job stayer sample. Distributions of four-quarter log hourly wage changes pooled over all years from 1998:3 to 2014:1. The first and last bar of the histogram contain all observations smaller than -0.255 and observations exceeding 0.255 , respectively. 
Figure A.4: Kelley Skewness of Hourly Wage, Earnings, and Hours Change Distributions
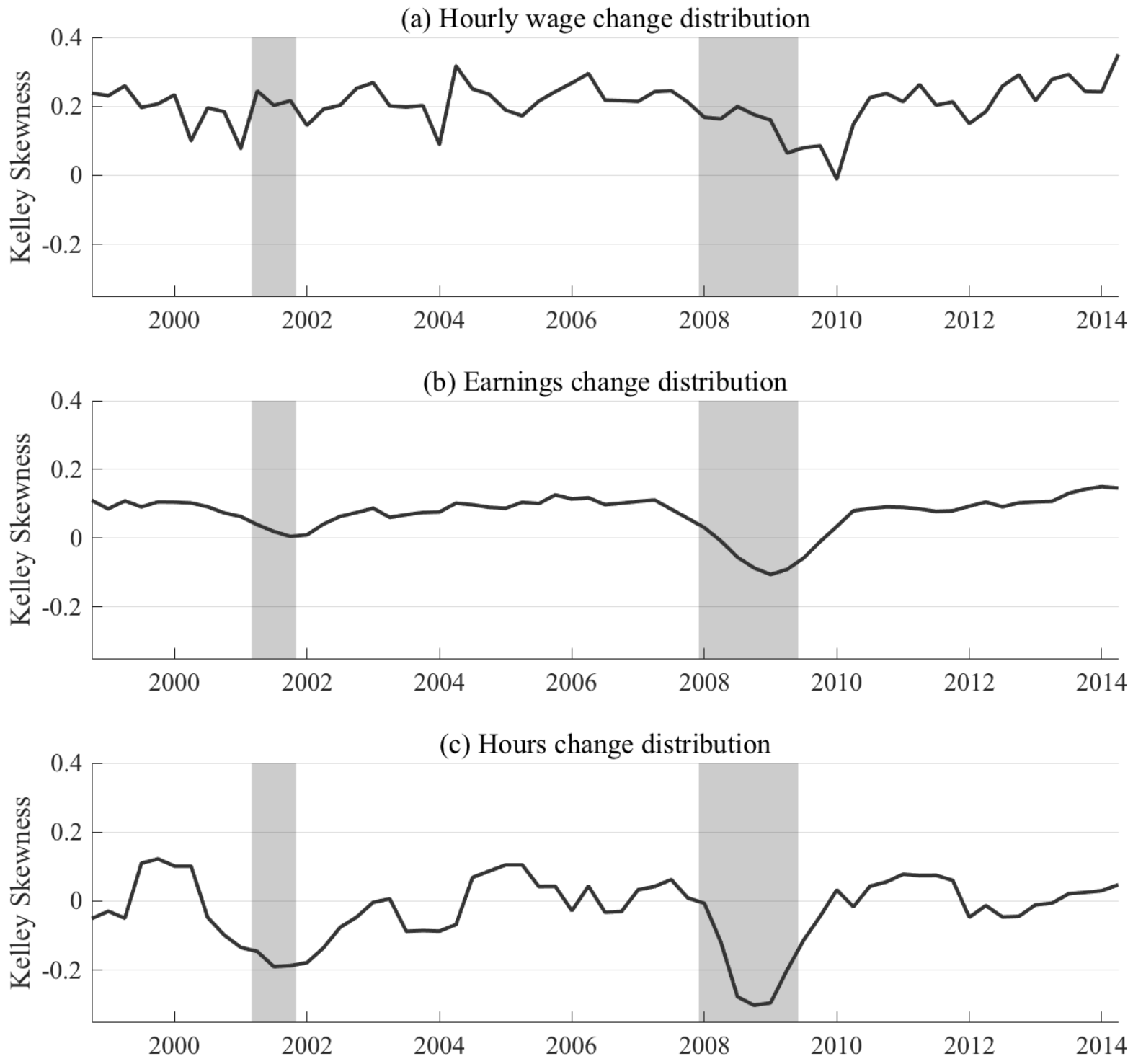

Notes: Washington state job stayer sample. Panel (a) shows Kelley skewness for each four-quarter log hourly wage change distribution from 1998:3 to 2014:1. Panel (b) and (c) show Kelley skewness for each year-to-year log earnings change and log hours change distribution, respectively, from 1998:3 to 2014:1. Grey bars show NBER recession dates. Kelley's skewness is calculated as $1-2 *\left(P_{50}-P_{10}\right) /\left(P_{90}-P_{10}\right)$ where $P_{10}, P_{50}$ and $P_{90}$ are the 10th, 50th and 90th percentile of the distribution, respectively. 
Figure A.5: Employment growth distributions of DNWR vs. non-DNWR firms
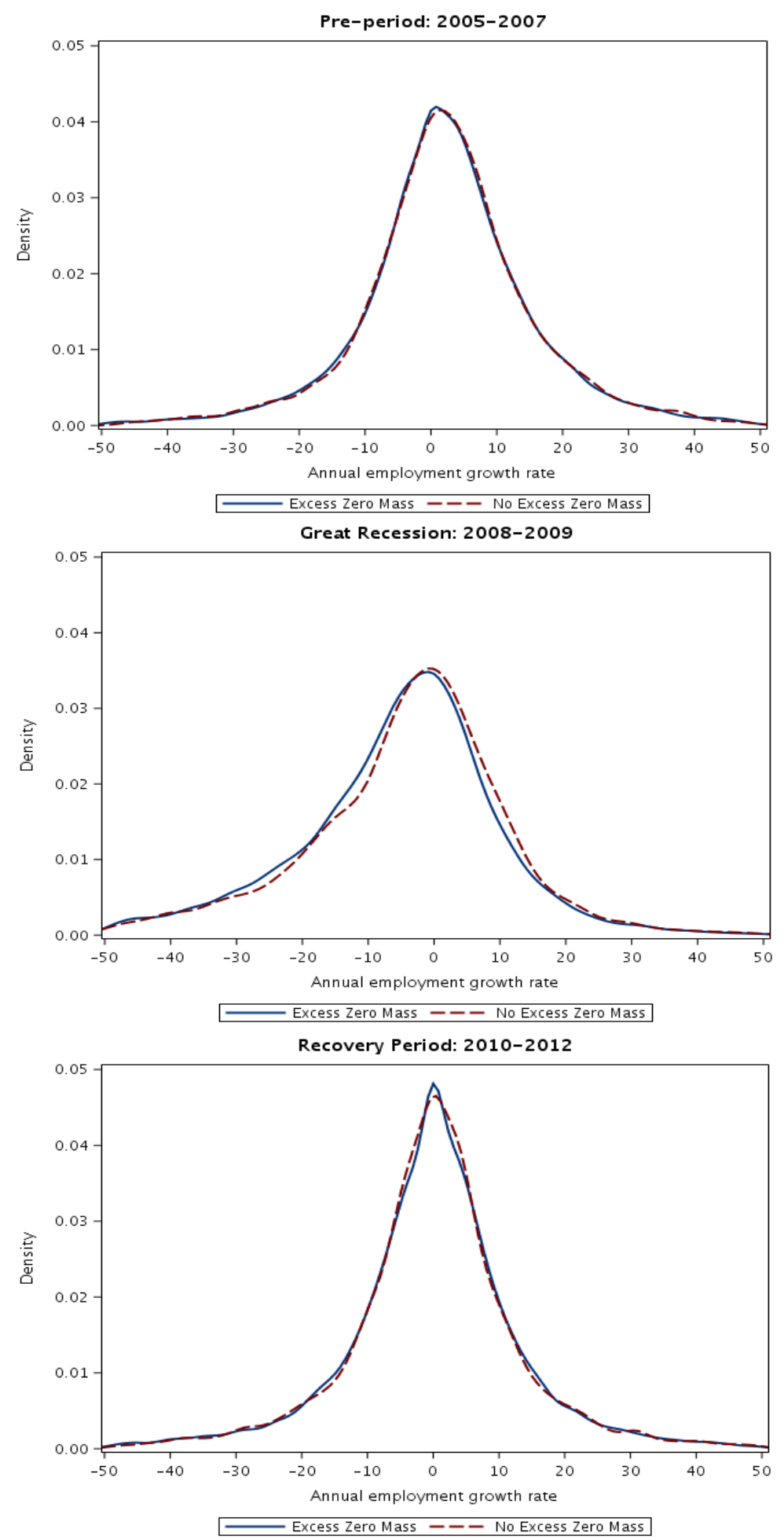

Notes: Washington state firm sample. The top graph shows pooled employment growth rates for 2004-2005, 2005-2006 and 2006-2007 for firms with and without an excess zero spike in their wage change distribution during 2004-07. The middle and bottom graphs show the same pooled employment growth rate for 2007-08 and 2008-09, respectively for 2010-2011 and 2011-2012. 